\title{
Friction and Wear of Polymer and Composites
}

\author{
Dewan Muhammad Nuruzzaman and Mohammad Asaduzzaman Chowdhury
}

Additional information is available at the end of the chapter

http://dx.doi.org/10.5772/48246

\section{Introduction}

Polymer and its composites are finding ever increasing usage for numerous industrial applications in sliding/rolling components such as bearings, rollers, seals, gears, cams, wheels, piston rings, transmission belts, grinding mills and clutches where their self lubricating properties are exploited to avoid the need for oil or grease lubrication with its attendant problems of contamination [1]. However, when the contact between sliding pairs is present, there is the problem of friction and wear. Yamaguchi [2], Hooke et al. [3] and Lawrence and Stolarski [4] reported that the friction coefficient can, generally, be reduced and the wear resistance increased by selecting the right material combinations.

Several researchers [5-7] observed that the friction force and wear rate depend on roughness of the rubbing surfaces, relative motion, type of material, temperature, normal force, stick slip, relative humidity, lubrication and vibration. The parameters that dictate the tribological performance of polymer and its composites also include polymer molecular structure, processing and treatment, properties, viscoelastic behavior, surface texture etc. [8-11]. There have been also a number of investigations exploring the influence of test conditions, contact geometry and environment on the friction and wear behavior of polymers and composites. Watanabe [12], Tanaka [13] and Bahadur and Tabor [14] reported that the tribological behavior of polyamide, high density polyethylene (HDPE) and their composites is greatly affected by normal load, sliding speed and temperature. Pihtili and Tosun $[15,16]$ showed that applied load and sliding speed play significant role on the wear behavior of polymer and composites. They also showed that applied load has more effect on the wear than the speed for composites. Several authors [17-22] observed that the friction coefficient of polymers and its composites rubbing against metals decreases with the increase in load though some other researchers have different views. Stuart [23] and other researchers [2426] showed that value of friction coefficient increases with the increase in load. Friction coefficient and specific wear rate values for different combinations of polymer and its composite were obtained and compared [27]. For all material combinations, it was observed 
that the coefficient of friction decreases linearly with the increase in applied pressure values. Unal et al. $[28,29]$ reported that the applied load exerts greater influence on the sliding wear of polymer and its composite than the sliding velocity.

Friction and wear behavior of glass fiber reinforced polyster composite were studied and results showed that in general, friction and wear are strongly influenced by all the test parameters such as applied load, sliding speed, sliding distance and fiber orientations [30]. Moreover, it was found that applied normal load, sliding speed and fiber orientations have more pronounced effect on wear rate than sliding distance. Wang and Li [31] observed that the sliding velocity has more significant effect on the sliding wear as compared to the applied load and variations of wear rate with operating time can be distinguished by three distinct periods. These periods are running-in period, steady-state period and severe wear period, respectively. Tsukizoe and Ohmae [32] showed that reinforcement of fiber or filler significantly improve the tribological behavior of polymeric material but this is not necessarily true for all cases. Suresha et al. [33] showed that there is a strong interdependence on the friction coefficient and wear loss with respect to the applied loads for steel-composites contact.

Friction process with vibration is an important practical phenomenon because the influence of vibration can cause significant change in this process. It is known that vibration and friction are dependent on each other. Friction generates vibration in various forms, while vibration affects friction in turns. Some explanations [34-38] are given in order to justify the decrease in the friction coefficient under vibration condition though some of the researchers have different views. Skare and Stahl [39] claimed that mean friction force increases as well as decreases depending on the vibration parameters.

Friction may be increased or decreased depending on the sliding pairs and operating parameters. In this chapter, friction coefficient and wear rate of different types of polymer and composite materials sliding against steel counterface are described. Effects of duration of rubbing, normal load, sliding speed, vertical vibration, horizontal vibration, natural frequency of vibration on friction coefficient are discussed. Some correlations of friction coefficient and wear rate are also incorporated in this chapter.

\section{Effect of duration of rubbing on friction coefficient}

In sliding contacts, friction coefficient varies with duration of rubbing and these variations are different at different normal loads and sliding velocities. Research works were carried out to investigate the friction coefficient with duration of rubbing for different types of composite and polymer materials. Figure 1 shows the variation of friction coefficient with the duration of rubbing at different normal loads for gear fiber [40]. For normal load $10 \mathrm{~N}$, curve 1 shows that during initial stage of rubbing, friction coefficient is low which remains constant for few minutes then increases very steadily up to a maximum value over a certain duration of rubbing and after that it remains constant for the rest of the experimental time [40].

At initial stage of rubbing, friction force is low due to contact between superficial layer of pin and disc and then, friction coefficient increases due to ploughing effect which causes 


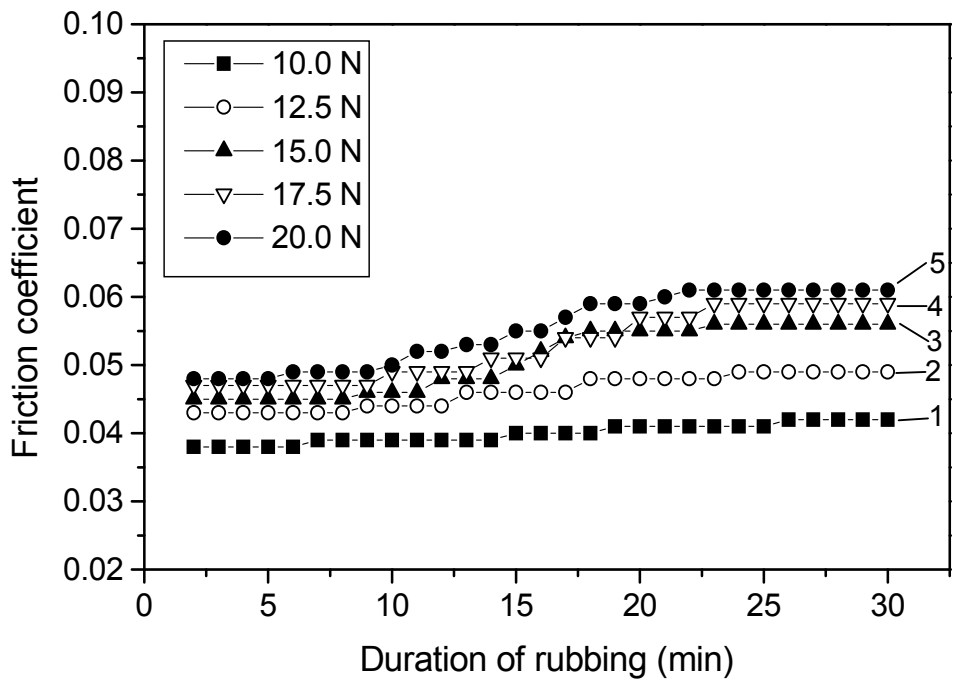

Figure 1. Friction coefficient as a function of duration of rubbing at different normal load, sliding velocity: $1 \mathrm{~m} / \mathrm{s}$, relative humidity: $70 \%$, test sample: gear fiber.

roughening of the test disc surface. For normal load $12.5 \mathrm{~N}$, curve 2 shows similar trend as that of curve 1. For normal loads $15,17.5$ and $20 \mathrm{~N}$, curves 3,4 and 5 show the friction results respectively. The increase in friction coefficient with the increase in normal load is due to the detachment and removal of worn materials and more contact with reinforced cloth fibers and the higher the normal load, time to reach constant friction is less [40]. This is due to the fact that the surface roughness and other parameters attain a steady level at shorter period with the increase in normal load [40].

Figure 2 shows the effect of the duration of rubbing on the value of friction coefficient at different normal loads for glass fiber. For normal load $10 \mathrm{~N}$, curve 1 shows that during initial stage of rubbing, friction coefficient rises for few minutes and then decreases very steadily up to a certain value over some duration of rubbing and then it becomes steady for the rest of the experimental time. Almost similar trends of variation are observed for loads $12.5,15,17.5$ and $20 \mathrm{~N}$ respectively and these results show that friction coefficient decreases with the increase in applied load [40]. It is known that tribological behavior of polymers and polymer composites can be associated with their viscoelastic and temperature-related properties. Sliding contact of two materials results in heat generation at the asperities and hence increases in temperature at the frictional surfaces of the two materials which influences the viscoelastic property in the response of materials stress, adhesion and transferring behaviors [27]. From these results, it can also be seen that time to reach constant friction is different for different normal loads and higher the normal load, glass fiber takes less time to stabilize [40]. Figure 3 shows the variation of friction coefficient with the duration of rubbing at different normal loads for nylon. For $10 \mathrm{~N}$ load, curve 1 indicates that during starting of the rubbing, the value of friction coefficient is low which increases for few minutes to a certain value and then decreases almost linearly over some duration of 


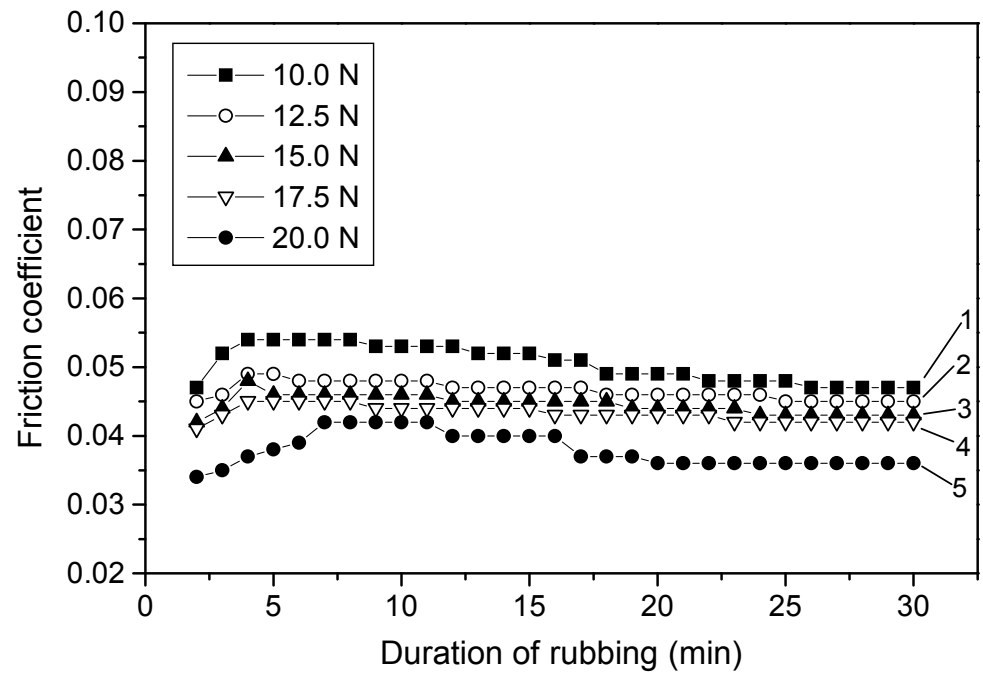

Figure 2. Friction coefficient as a function of duration of rubbing at different normal load, sliding velocity: $1 \mathrm{~m} / \mathrm{s}$, relative humidity: $70 \%$, test sample: glass fiber.

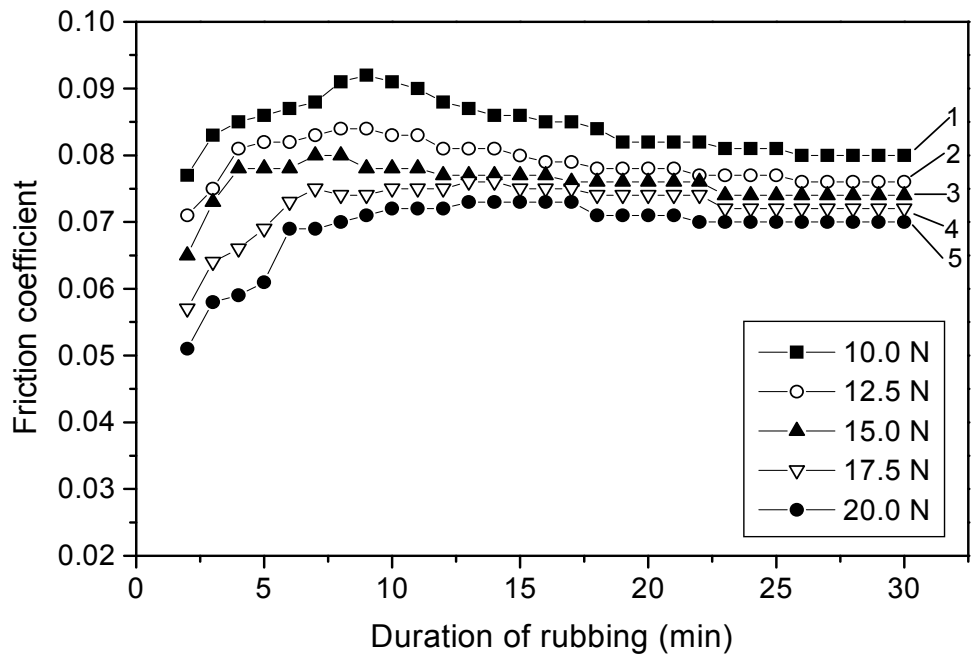

Figure 3. Friction coefficient as a function of duration of rubbing at different normal load, sliding velocity: $1 \mathrm{~m} / \mathrm{s}$, relative humidity: $70 \%$, test sample: nylon.

rubbing and after that it remains constant for the rest of the experimental time. Similar trends of variation are observed for normal loads 12.5, 15, 17.5 and $20 \mathrm{~N}$. In these cases, transfer film formed on the stainless steel couterface and the transfer film has important effects on the tribological behavior of a material [22, 40-42]. Friction and wear behavior of polymer sliding against a metal is strongly influenced by its ability to form a transfer film on the counterface [42]. The transfer film formed on a non-polymer counterface is controlled by the counterface material, roughness, and sliding conditions [2]. 


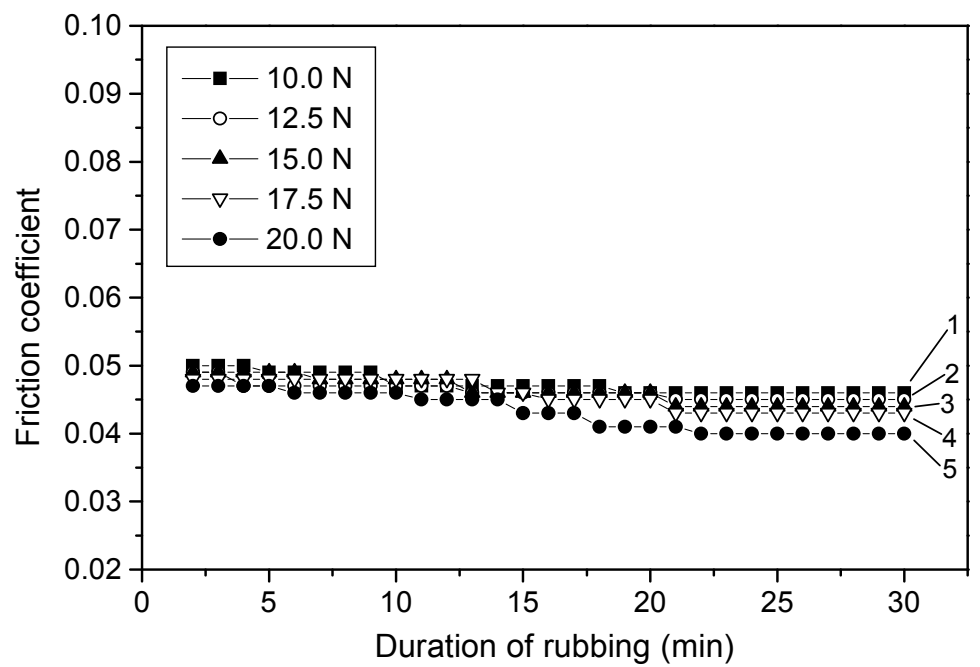

Figure 4. Friction coefficient as a function of duration of rubbing at different normal load, sliding velocity: $1 \mathrm{~m} / \mathrm{s}$, relative humidity: $70 \%$, test sample: PTFE.

Figure 4 for PTFE shows that friction coefficient decreases almost linearly up to certain value over some duration of rubbing and after that it remains constant for the rest of the experimental time. It can be noted that transfer film of PTFE formed on the steel counterface due to the strong adhesion across the interface $[40,43]$.

Friction coefficient varies with duration of rubbing at different sliding speeds for different composite and polymer materials [44]. These results are presented in Figs. 5-8.

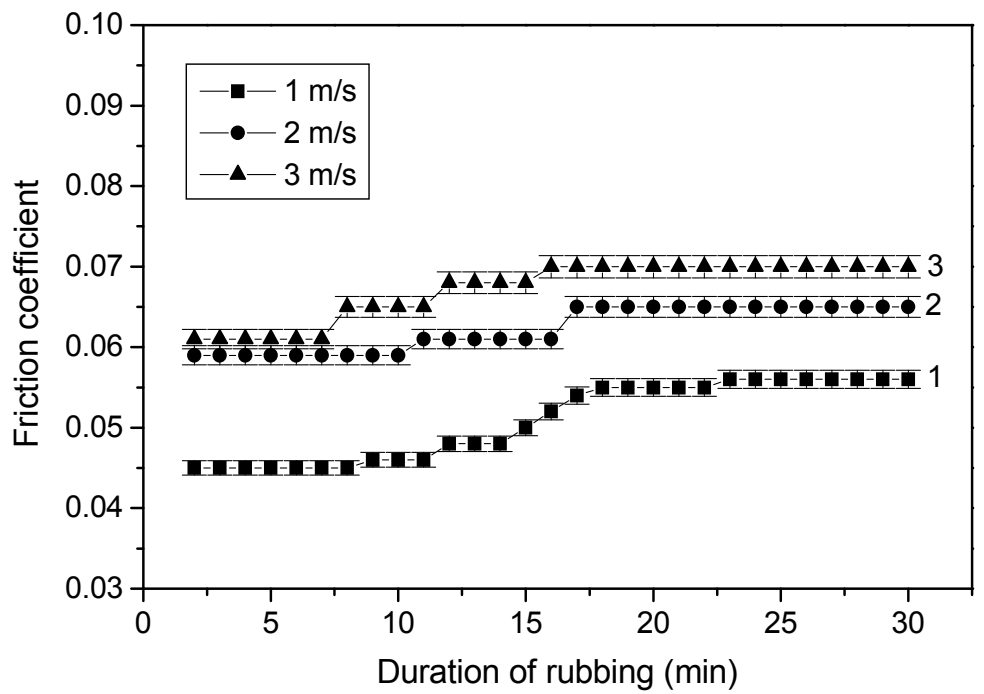

Figure 5. Friction coefficient as a function of duration of rubbing at different sliding speeds, normal load: $15 \mathrm{~N}$, relative humidity: $70 \%$, test sample: gear fiber. 


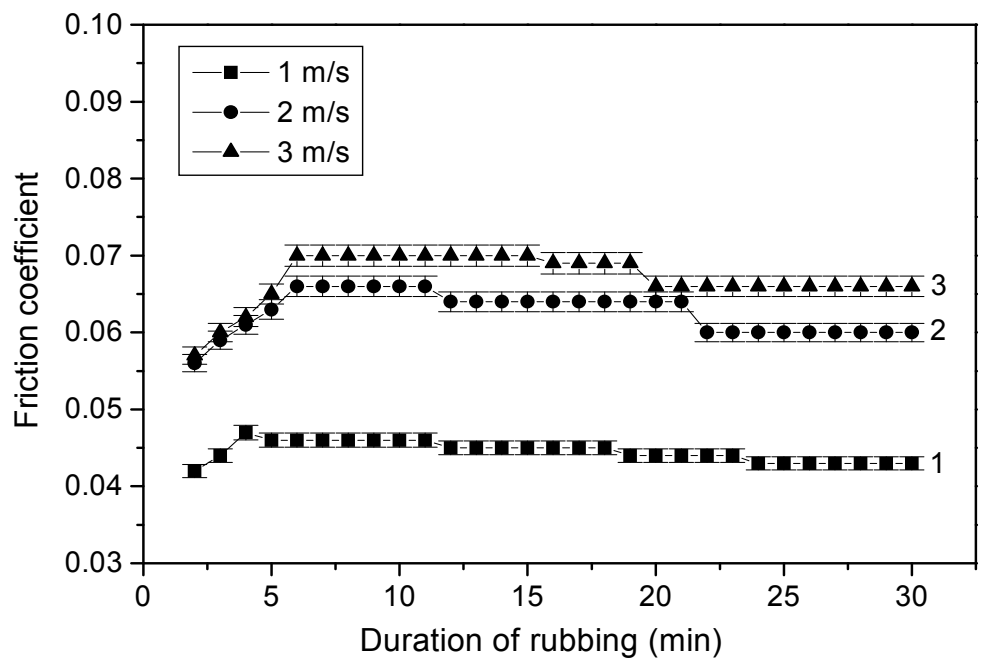

Figure 6. Figure 6. Friction coefficient as a function of duration of rubbing at different sliding speeds, normal load: $15 \mathrm{~N}$, relative humidity: $70 \%$, test sample: glass fiber.

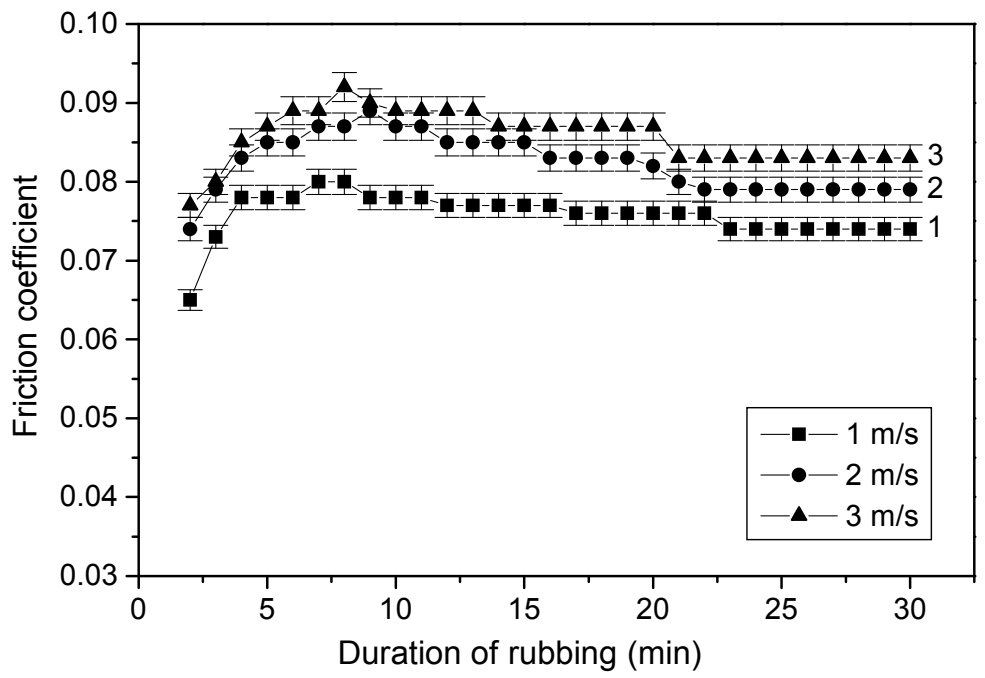

Figure 7. Friction coefficient as a function of duration of rubbing at different sliding speeds, normal load: $15 \mathrm{~N}$, relative humidity: $70 \%$, test sample: nylon. 


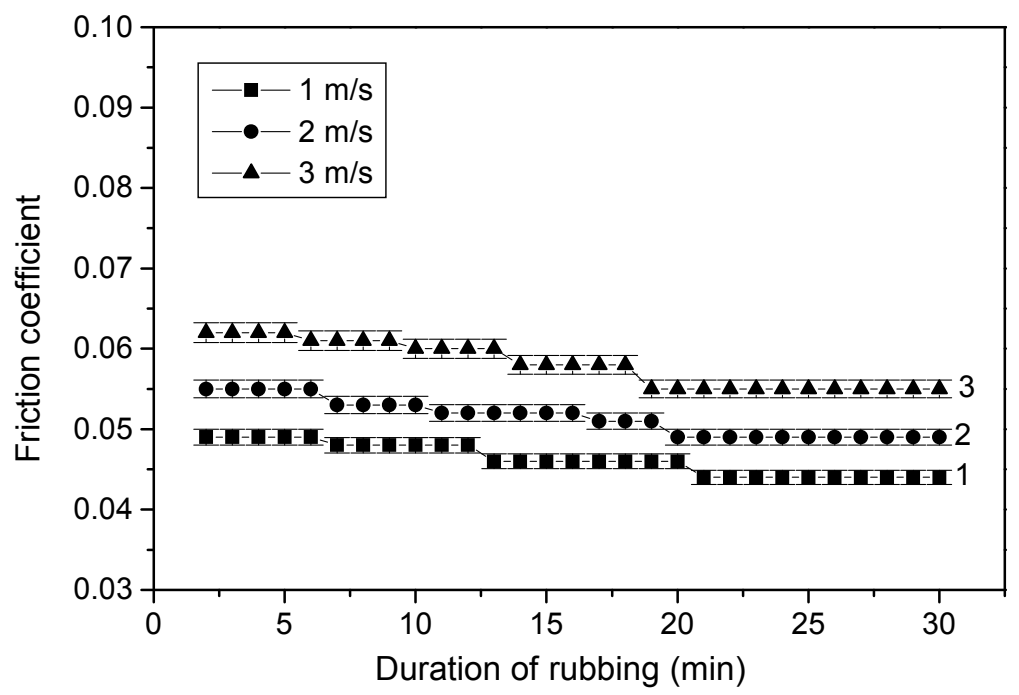

Figure 8. Friction coefficient as a function of duration of rubbing at different sliding speeds, normal load: $15 \mathrm{~N}$, relative humidity: $70 \%$, test sample: PTFE.

\section{Effect of normal load on friction coefficient and wear rate}

In this section, a comparison of the variation of friction coefficient with normal load for different materials has been discussed. Wear rates of different materials are also compared. Results of Fig. 9 show that friction coefficient decreases with the increase in normal load for glass fiber, PTFE and nylon. Different behavior is observed for gear fiber that is, friction coefficient of gear fiber increases with the increase in normal load. Some factors such as high ploughing, surface damage and breakage of reinforced fibers are responsible for higher friction with higher normal load [40]. Variations of wear rate with normal load for gear fiber, glass fiber, nylon and PTFE are shown in Fig. 10. This figure indicates that wear rate increases with the increase in normal load for all types of materials investigated. The shear force and frictional thrust are increased with the increase in applied load and these increments accelerate the wear rate. Figure 10 also shows the comparison of the variation of wear rate with normal load for gear fiber, glass fiber, nylon and PTFE. The highest values of wear rate for PTFE and lowest values for nylon are obtained among these materials. In case of composite materials, the values of wear rate are higher for gear fiber compared to that of glass fiber. For plastic materials, higher values are observed for PTFE compared to nylon [40]. 


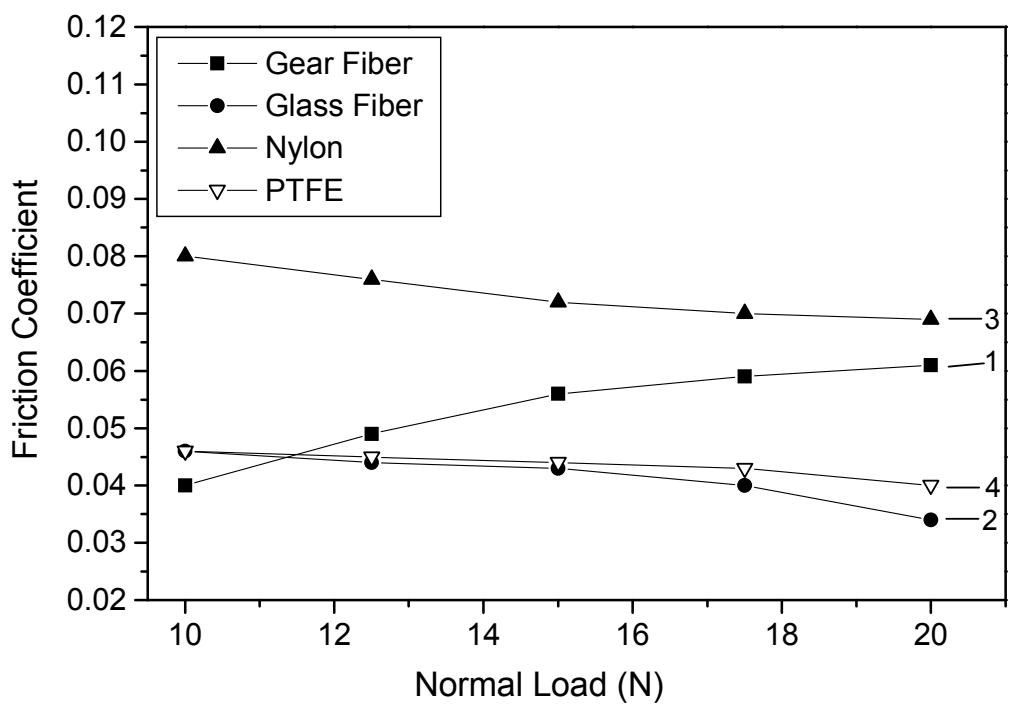

Figure 9. Friction coefficient as a function of normal load for different materials, sliding velocity: $1 \mathrm{~m} / \mathrm{s}$, relative humidity: $70 \%$.

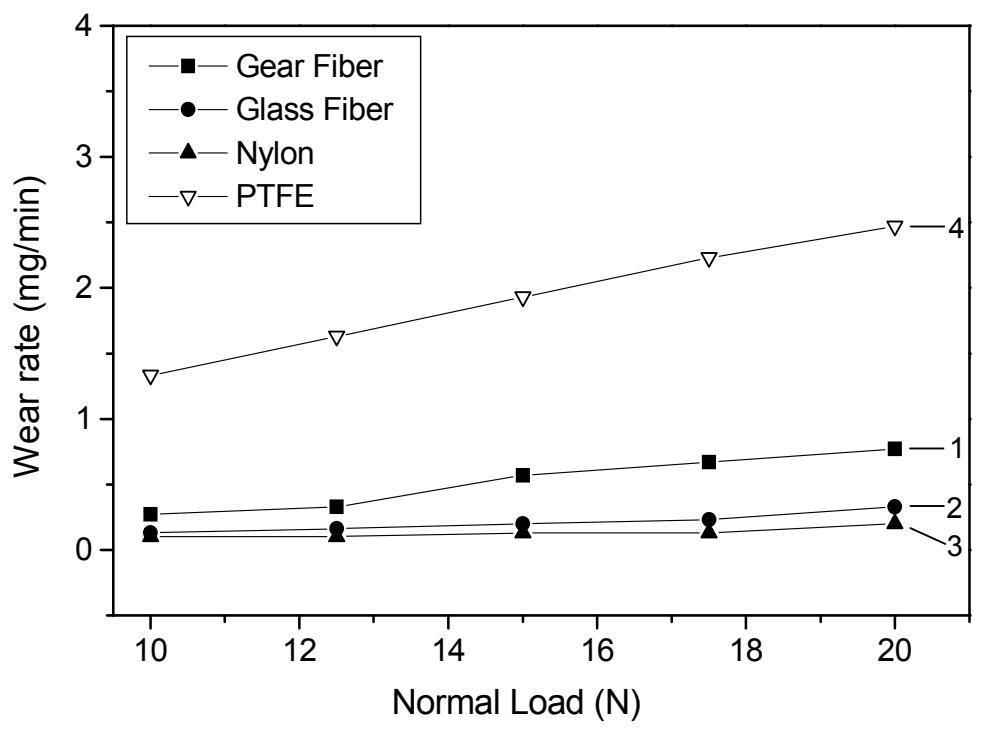

Figure 10. Wear rate as a function of normal load for different materials, sliding velocity: $1 \mathrm{~m} / \mathrm{s}$, relative humidity: $70 \%$. 


\section{Effect of sliding speed on friction coefficient and wear rate}

In sliding contacts, sliding speed has an important role on friction and wear of different polymer and composite materials. Figure 11 shows the comparison of the variation of friction coefficient with sliding speed for different materials. Results show that friction coefficient increase almost linearly with sliding speed [44]. These findings are in agreement with the findings of Mimaroglu et al. [27] and Unal et al. [45]. With the increase in sliding speed, the frictional heat may decrease the strength of the materials and high temperature results in stronger or increased adhesion with pin [27,43]. The increase of friction coefficient with sliding speed can be explained by the more adhesion of counterface pin material on disc. Figure 11 indicates that nylon shows the highest friction coefficient within the observed range of sliding speed. Results also reveal that PTFE shows the lowest friction coefficient among these four materials except at sliding speed $1 \mathrm{~m} / \mathrm{s}$. At sliding speed $1 \mathrm{~m} / \mathrm{s}$, glass fiber shows slightly lower friction coefficient than PTFE but at a sliding speed $3 \mathrm{~m} / \mathrm{s}$, glass fiber exhibits much higher friction coefficient than PTFE. This may be due to the breakage of reinforced glass fibers with the increase in sliding speed. Results also show that friction coefficient of gear fiber is higher than that of glass fiber and PTFE. This is due to ploughing effect and breakage of the exposed reinforced cloth fiber of the fracture material [44]. Variations of wear rate with sliding speed for gear fiber, glass fiber, nylon and PTFE are presented in Fig. 12. This figure shows that wear rate increases with the increase in sliding speed for all types of materials investigated. These findings are in agreement with the findings of Mimaroglu et al. [27] and Suresha et al. [33]. The shear force, frictional heat and

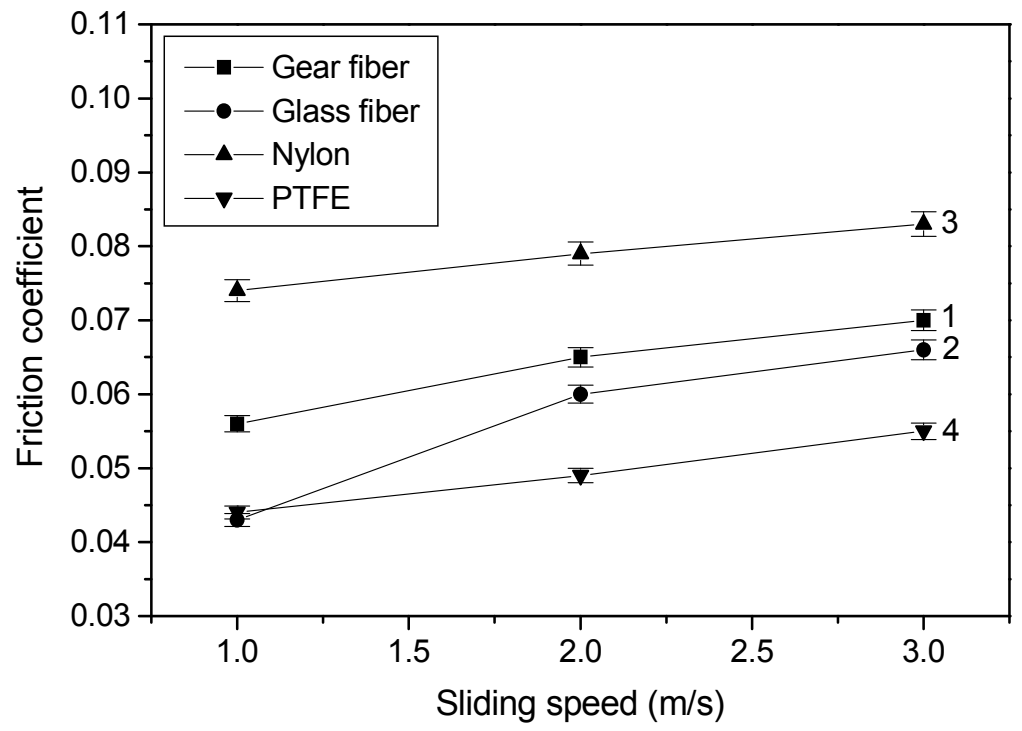

Figure 11. Friction coefficient as a function of sliding speed for different materials, normal load: $15 \mathrm{~N}$, relative humidity: $70 \%$. 


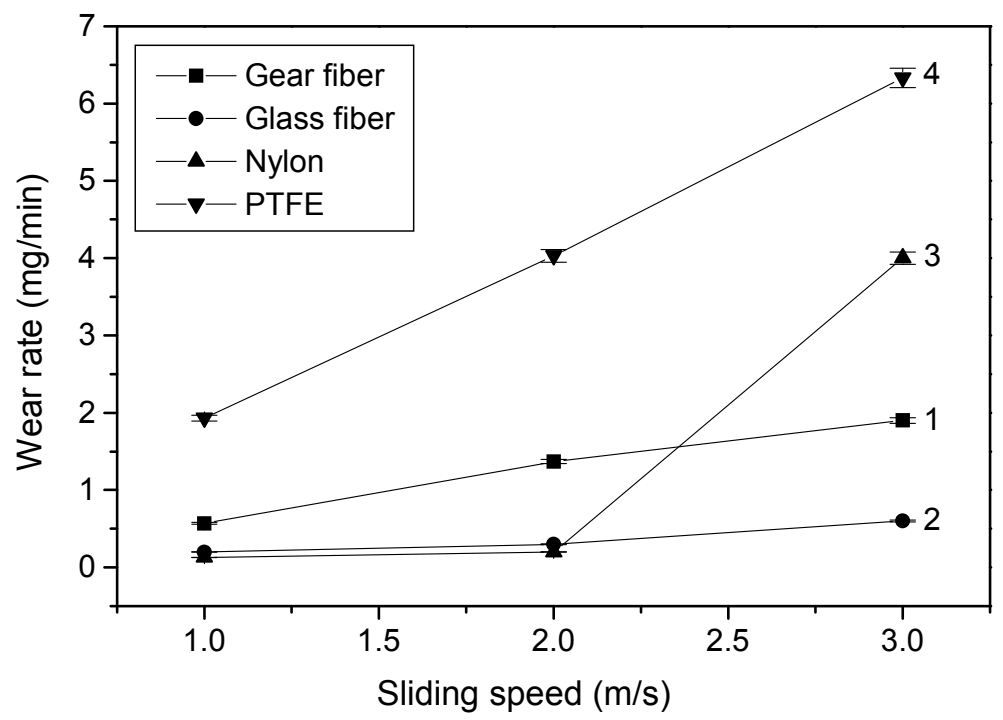

Figure 12. Wear rate as a function of sliding speed for different materials, normal load: $15 \mathrm{~N}$, relative humidity: $70 \%$.

frictional thrust are increased with the increase in sliding speed and these increments accelerate the wear rate. Figure 12 also shows the comparison of the variation of wear rate with sliding speed for gear fiber, glass fiber, nylon and PTFE. From this figure it is observed that PTFE has the highest wear rate among these four materials within the observed range of sliding speed. It is also observed that nylon has the lowest wear rate among these four materials except at sliding speed $3 \mathrm{~m} / \mathrm{s}$. At sliding speed $3 \mathrm{~m} / \mathrm{s}$, wear rate of nylon is higher than that of gear fiber and glass fiber. Because of higher sliding speed, loss of strength is higher for nylon [43] compared to that of other materials. In case of composite materials, the values of wear rate are higher for gear fiber compared to that of glass fiber [44].

\section{Effect of vertical vibration}

Figure 13 shows the pin-on-disc set-up with vertical vibration arrangement [46]. For generating vertical vibration, there are two circular plates near the bottom end of the shaft. The upper circular plate fitted with the bottom end of the shaft has a spherical ball in such a way that the ball is extended from the lower surface of this plate. On the top surface of the lower circular plate there are a number of slots. When the shaft rotates, the ball of the upper circular plate slides on the slotted surface of the lower circular plate and due to the spring action, the shaft along with the rotating plate vibrates. The direction of vibration is vertical, i.e. perpendicular to the sliding direction of the pin. By varying the shaft rotation and the number of slots of the lower circular vibration generating plate, the frequency of vibration is varied. By adjusting the height of this slotted plate, the amplitude of the vibration is varied. 


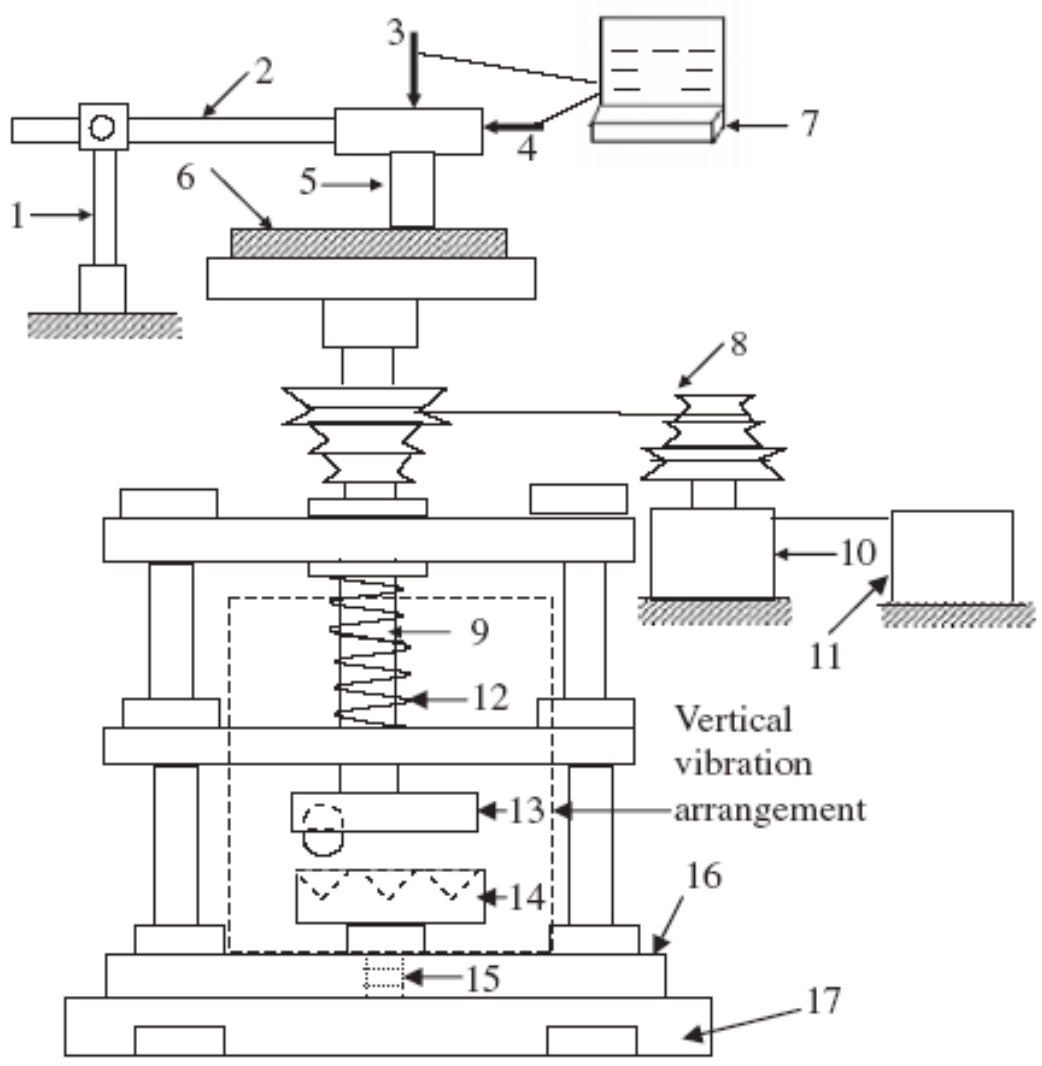

Figure 13. Schematic diagram of the experimental set-up for vertical vibration (1) Load arm holder (2) Load arm (3) Normal load (4) Horizontal load (5) Pin sample (6) Test disc with rotating table (7) Computer (8) Belt and pulley (9) Main shaft (10) Motor (11) Speed control unit (12) Compression spring (13) Upper plate with ball (14) Lower plate with V-slots (15) Height adjustable screw (16) Base plate (17) Rubber block

\subsection{Friction coefficient with duration of rubbing at different amplitudes of vibration}

The presence of external vertical vibration affects the friction force of different materials considerably which is discussed in this section. Figures 14-17 show the variation of friction coefficient with the duration of rubbing and amplitude of vibration for different types of material. Variations of friction coefficient with time of rubbing for glass fiber reinforced plastic (glass fiber), cloth reinforced ebonite (gear fiber), PTFE and rubber are presented in Figs. 14-17, respectively. These figures indicate that time to reach steady-state value is different for different materials. 
Research works carried out for different materials at different frequencies of vibration and these results show that time to reach constant friction is same for these materials [46]. Results also reveal that friction coefficient decrease with the increase in amplitude of vibration. This is due to the fact that the greater the amplitude of vibration, the higher the

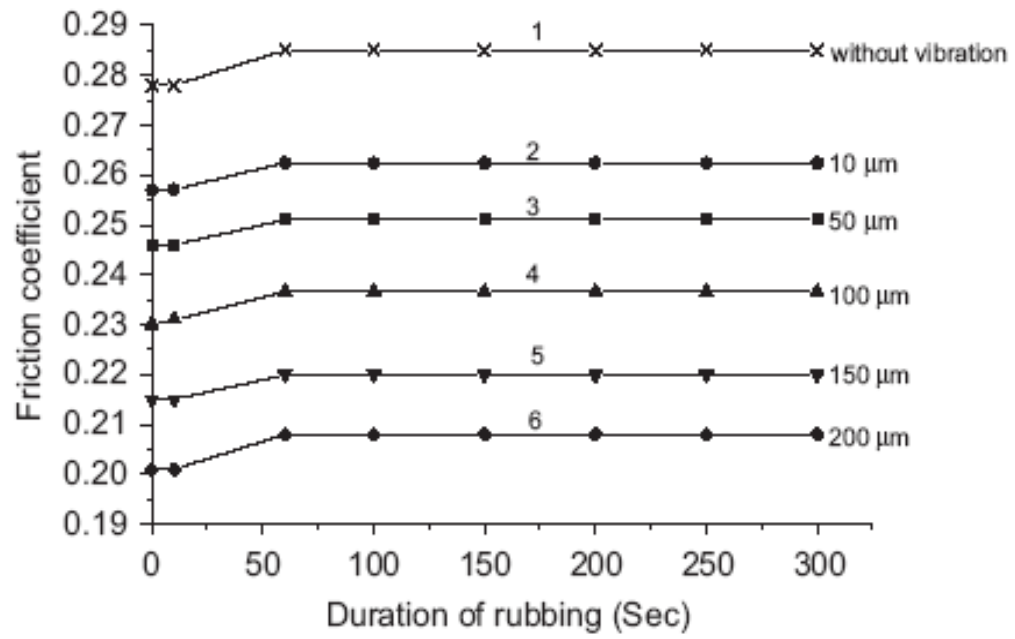

Figure 14. Variation of friction coefficient with the variation of duration of rubbing at different amplitude of vibration (sliding velocity: $0.785 \mathrm{~m} / \mathrm{s}$, normal load: $10 \mathrm{~N}$, frequency of vibration: $500 \mathrm{~Hz}$, roughness: $0.2 \mu \mathrm{m}$ (RMS), relative humidity: $50 \%$, test sample: glass fiber reinforced plastic).

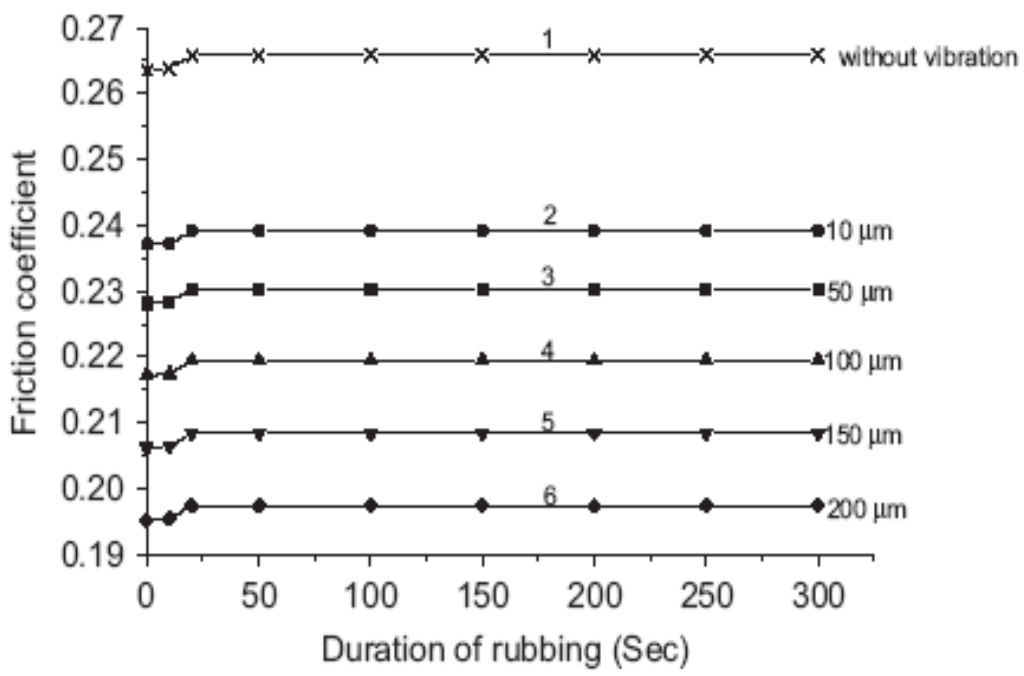

Figure 15. Variation of friction coefficient with the variation of duration of rubbing at different amplitude of vibration (sliding velocity: $0.785 \mathrm{~m} / \mathrm{s}$, normal load: $10 \mathrm{~N}$, frequency of vibration: $500 \mathrm{~Hz}$, roughness: $0.2 \mu \mathrm{m}$ (RMS), relative humidity: $50 \%$, test sample: cloth reinforced ebonite). 


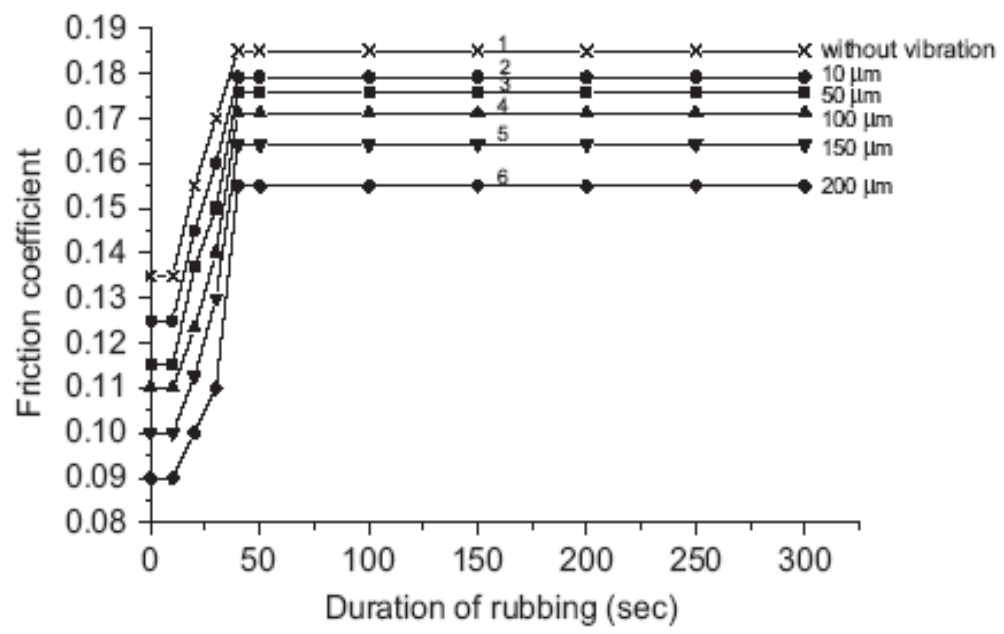

Figure 16. Variation of friction coefficient with the variation of duration of rubbing at different amplitude of vibration (sliding velocity: $0.785 \mathrm{~m} / \mathrm{s}$, normal load: $10 \mathrm{~N}$, frequency of vibration: $150 \mathrm{~Hz}$, roughness: $1.5 \mu \mathrm{m}$ (RMS), relative humidity: 50\%, test sample: PTFE).

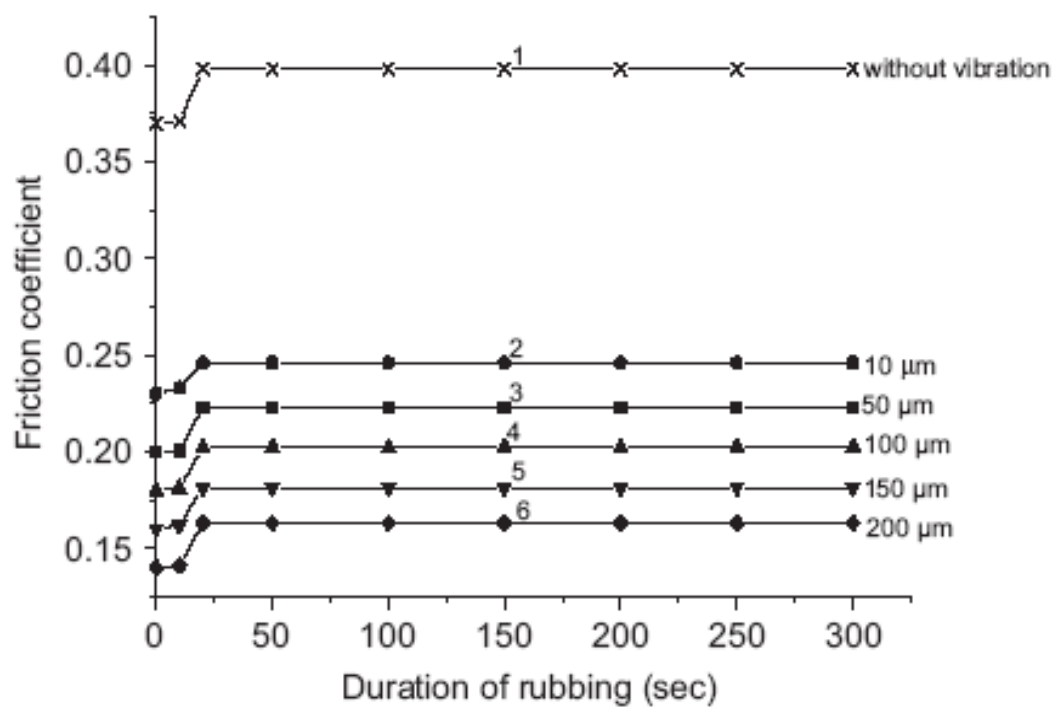

Figure 17. Variation of friction coefficient with the variation of duration of rubbing at different amplitude of vibration (sliding velocity: $0.0393 \mathrm{~m} / \mathrm{s}$, normal load: $10 \mathrm{~N}$, frequency of vibration: $50 \mathrm{~Hz}$, roughness: $1.5 \mu \mathrm{m}$ (RMS), relative humidity: $50 \%$, test sample: rubber).

actual rubbing time, because there is always more separation between the rubbing surfaces due to reduction in the mean contact area of the two sliding objects for vibration [38]. Therefore, the reduction of friction coefficient for the increase in amplitude of vibration is 
due to the separation of contact surfaces as the higher the amplitude the higher the separation of rubbing surfaces. In fact the higher the separation, the higher the time of contact between the rubbing surfaces is required. As the amplitude increases, keeping the frequency of vibration constant, the acceleration of vibration will also increase that might cause momentary vertical load reduction, which causes the reduction of effective normal force resulting reduction of friction coefficient with the increase of amplitude of vibration. The factors responsible for this momentarily load reduction are: (i) superposition of static and dynamic force generated during vibration, (ii) reversal of the friction vector, (iii) local transformation of vibration energy into heat energy, and (iv) approaching excitation frequency to resonance frequency, etc.

\subsection{Friction coefficient at different amplitudes and frequencies of vibration}

Amplitude and frequency of vibration have a major role on friction coefficient which is discussed in this section. The effects of amplitude of vibration on the friction coefficient at different frequencies for different materials are shown in Figs. 18-21. Results represent that friction coefficient decreases with the increase in amplitude of vibration at different frequencies of vibration at different rates for different materials. This decrease in friction coefficient is nearly linear for glass fiber, gear fiber and rubber but that for PTFE is nonlinear and its rate is increasing with higher amplitude of vibration [46]. Results also reveal that friction coefficient decreases with the increase in frequency of vibration. These findings are in agreement the findings for mild steel [7].

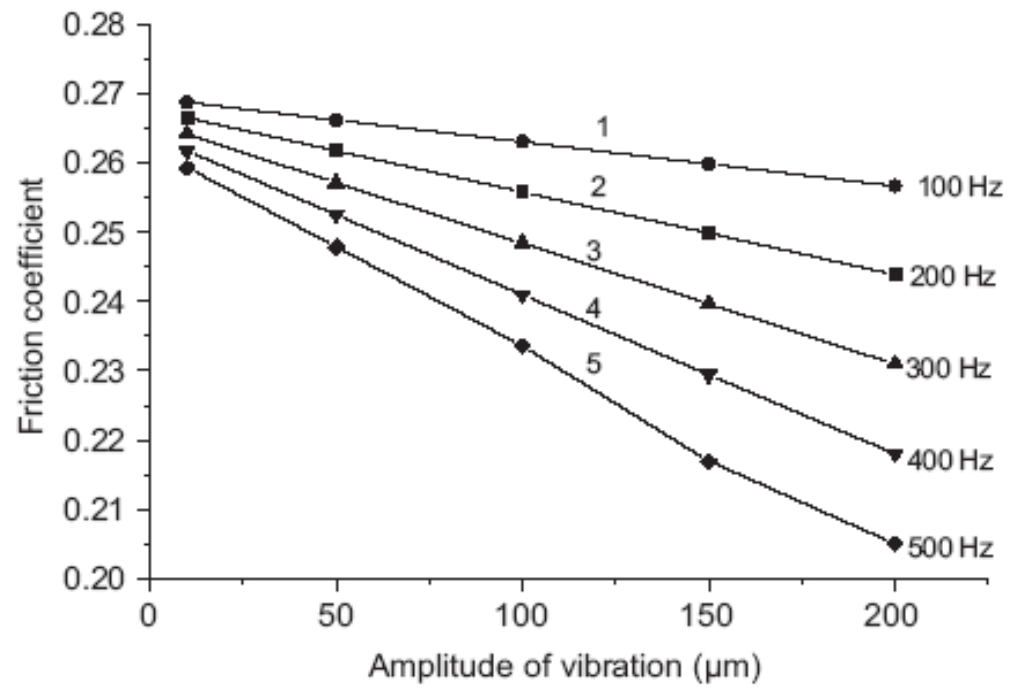

Figure 18. Variation of friction coefficient with the variation of amplitude of vibration at different frequency of vibration (sliding velocity: $1.17 \mathrm{~m} / \mathrm{s}$, normal load: $10 \mathrm{~N}$, roughness: $0.2 \mu \mathrm{m}$ (RMS), relative humidity: $50 \%$, test sample: glass fiber reinforced plastic). 


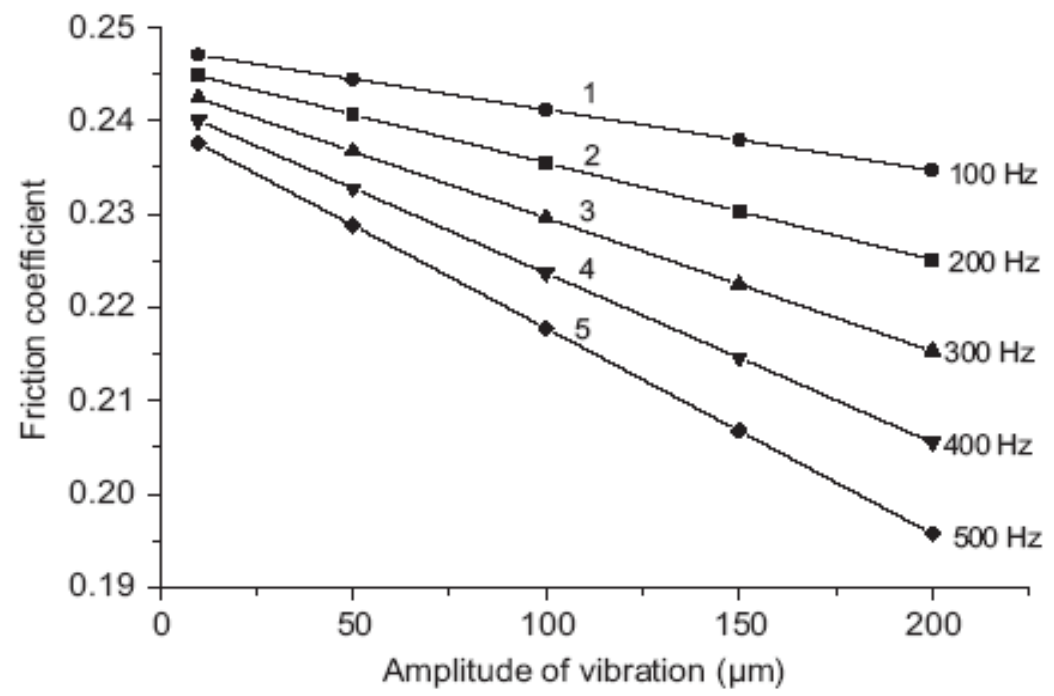

Figure 19. Variation of friction coefficient with the variation of amplitude of vibration at different frequency of vibration (sliding velocity: $1.17 \mathrm{~m} / \mathrm{s}$, normal load: $10 \mathrm{~N}$, roughness: $0.2 \mu \mathrm{m}$ (RMS), relative humidity: 50\%, test sample: cloth reinforced ebonite).

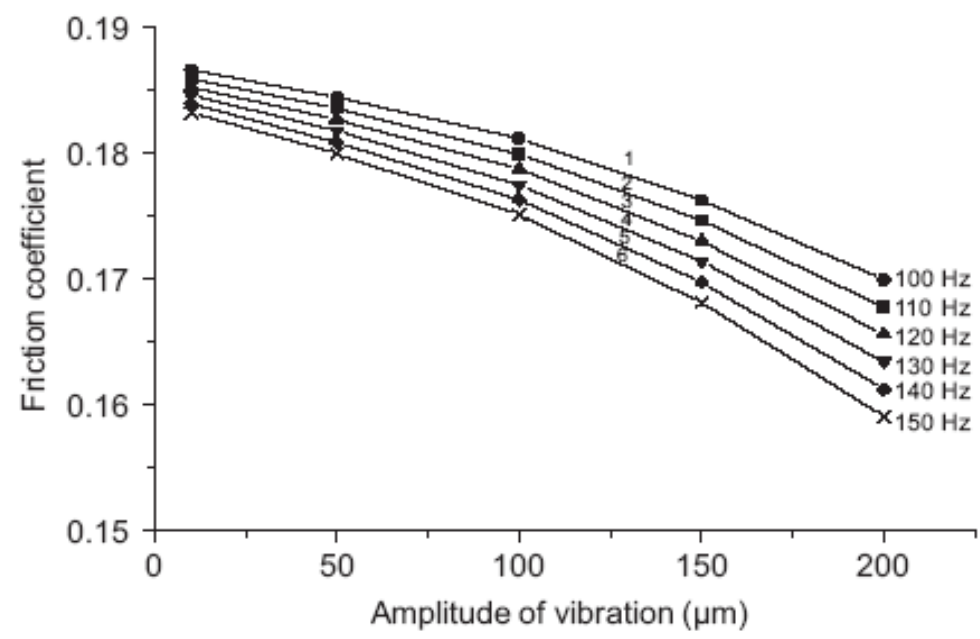

Figure 20. Variation of friction coefficient with the variation of amplitude of vibration at different frequency of vibration (sliding velocity: $1.17 \mathrm{~m} / \mathrm{s}$, normal load: $10 \mathrm{~N}$, roughness: $1.5 \mu \mathrm{m}$ (RMS), relative humidity: 50\%, test sample: PTFE). 


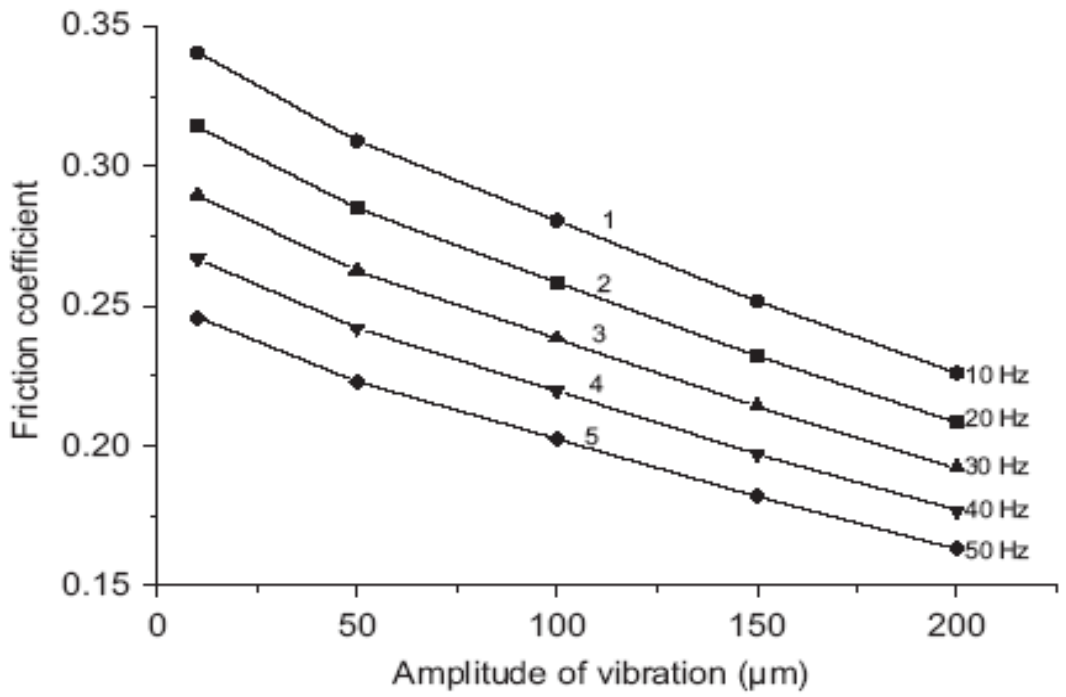

Figure 21. Variation of friction coefficient with the variation of amplitude of vibration at different frequency of vibration (sliding velocity: $0.0393 \mathrm{~m} / \mathrm{s}$, normal load: $10 \mathrm{~N}$, roughness: $1.5 \mu \mathrm{m}$ (RMS), relative humidity: $50 \%$, test sample: rubber).

Friction coefficients of GFRP, mild steel and ebonite are compared for different conditions of vibration (frequency: 100 to $500 \mathrm{~Hz}$ and amplitude: 0 to $200 \mu \mathrm{m}$ ) of similar hardness range [47]. These results are presented in Figs. 22-26. Results show that the magnitude and the slope of line of friction coefficient of mild steel are higher than that of GFRP and ebonite. This might be due to the lack of rigidity and strength of the asperities of ebonite and GFRP than mild steel. The variation of friction coefficient with the variation of materials also depends on different physical properties of mating materials and adhesion which depends on inter-atomic force, surface free energy, van der Waals forces, interface condition and chemical interaction due to different types of bonding [43]. It can be noted that at lower frequency $(100 \mathrm{~Hz})$, the magnitude of friction coefficient of mild steel is varied significantly than GFRP and ebonite. This variation decreases with the increase in frequency of vibration and at higher frequency $(500 \mathrm{~Hz})$, the values friction coefficient of mild steel are almost similar to the friction values of GFRP and ebonite. Under similar conditions, the values of friction coefficient of GFRP are higher than that of ebonite. 


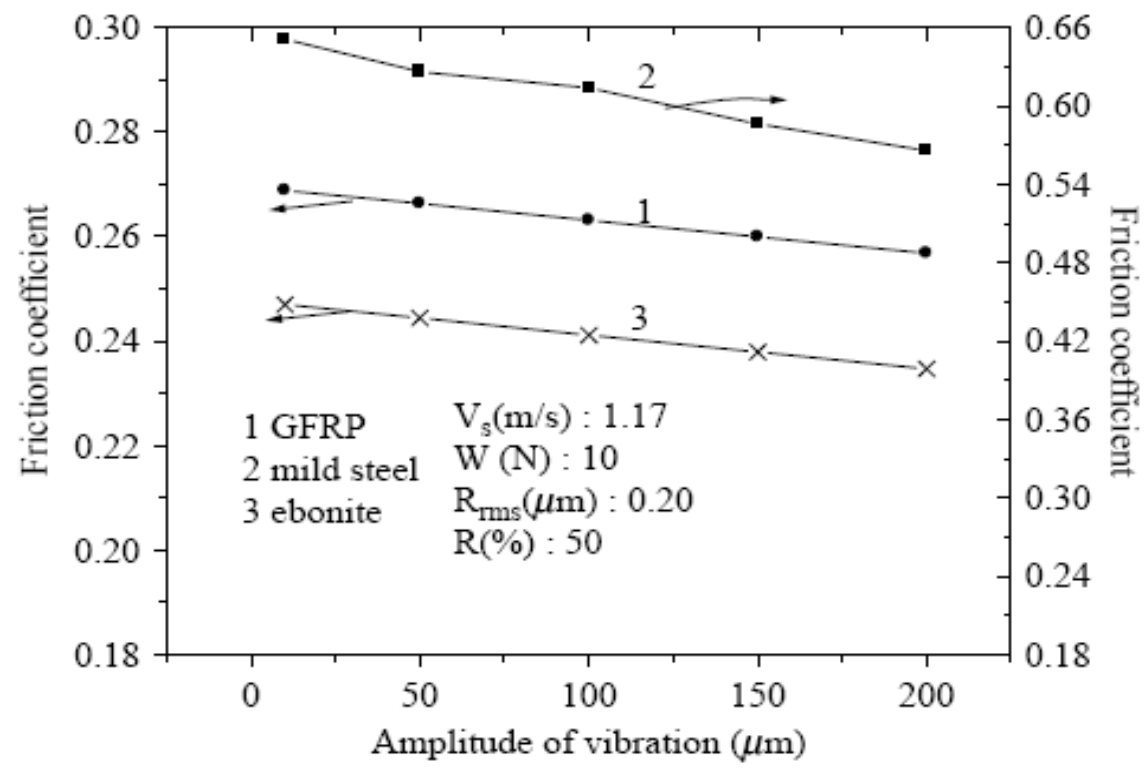

Note: $f(H z): 100$

Figure 22. Variation of friction coefficient with the variation of amplitude of vertical vibration

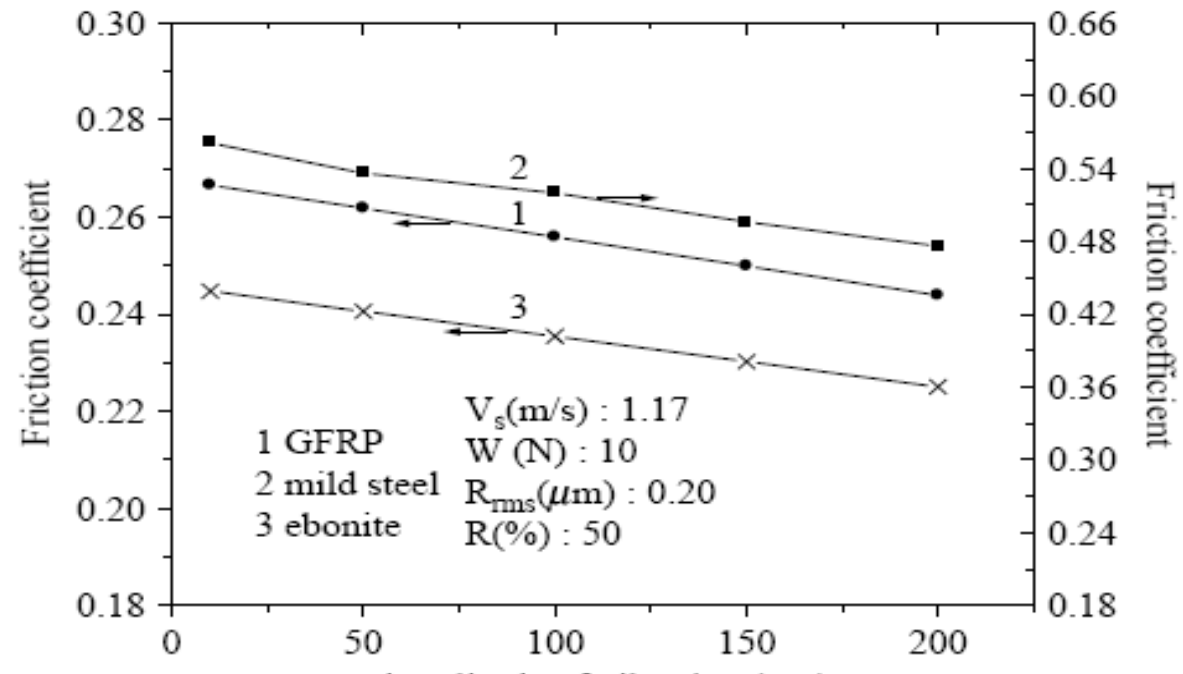

Note: $\mathrm{f}(\mathrm{Hz}): 200$

Amplitude of vibration $(\mu \mathrm{m})$

Figure 23. Variation of friction coefficient with the variation of amplitude of vertical vibration 


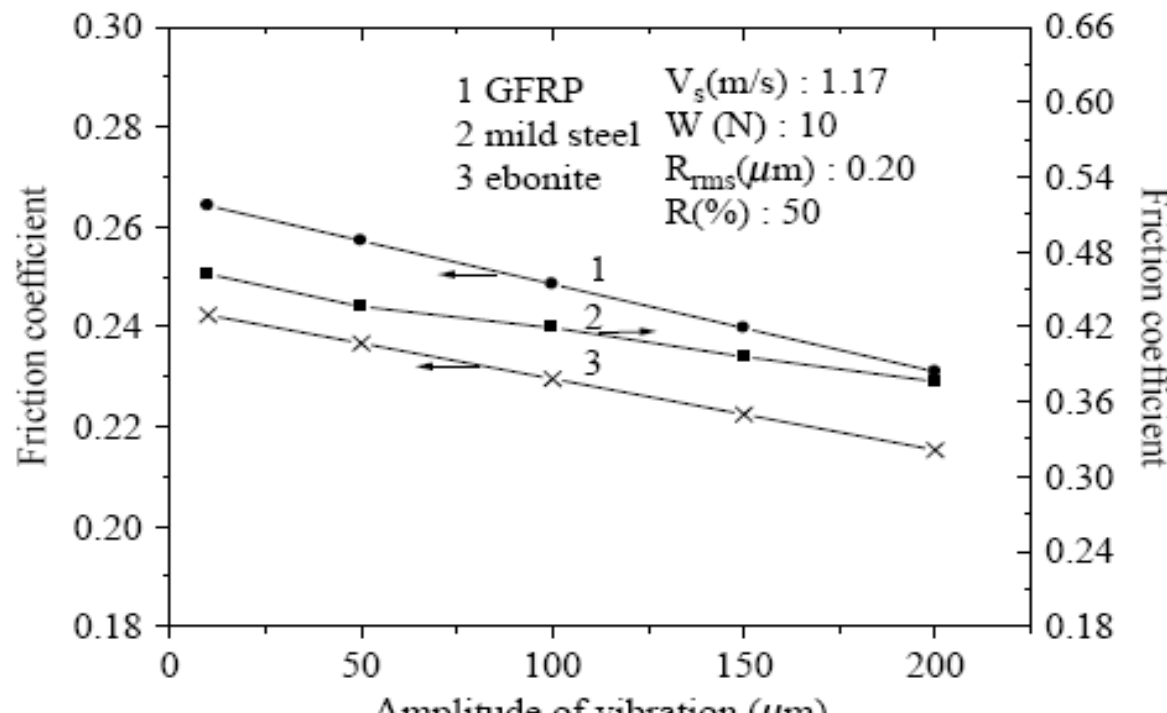

Note: $\mathrm{f}(\mathrm{Hz}): 300$

Figure 24. Variation of friction coefficient with the variation of amplitude of vertical vibration

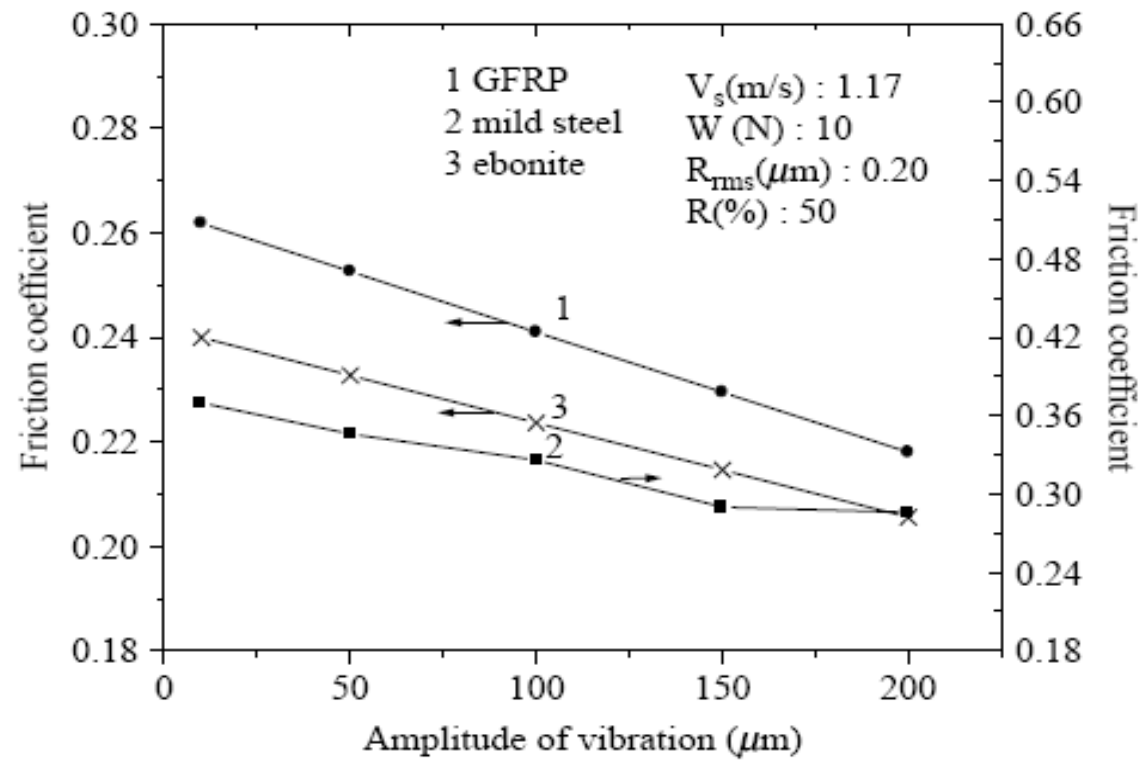

Note: $\mathrm{f}(\mathrm{Hz}): 400$

Figure 25. Variation of friction coefficient with the variation of amplitude of vertical vibration 


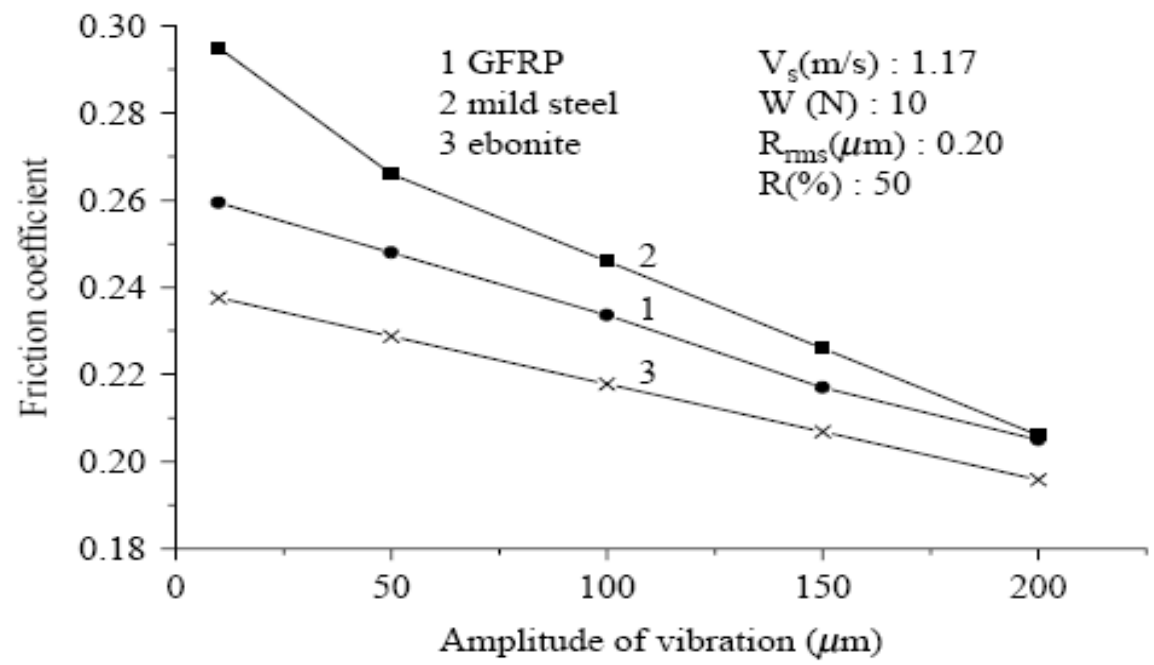

Note: $f(H z): 500$

Figure 26. Variation of friction coefficient with the variation of amplitude of vertical vibration

\section{Effect of horizontal vibration}

The pin-on-disc set-up (Fig. 27) used for generating horizontal vibration [48] in which one end of a coil spring is fixed with the rotating shaft and other end of the spring is fixed with the Vslotted rotating table. An adjusting rigid barrier with spherical tip is fixed with the basic structure of the set-up. Owing to spring action and rotation, the table vibrates horizontally. The direction of vibration is either longitudinal (along the direction of sliding velocity) or transverse (along perpendicular to the direction of sliding velocity) depending on the position of sliding pin on the rotating vibrating table. By varying rotation of the shaft and the number of slots of the rotating table, the frequency of vibration is varied. By adjusting the depth of penetration of the adjustable barrier, the amplitude of the vibration is varied.

The frictional behavior of composite materials under external horizontal vibration is presented in this section. Friction coefficients of GFRP, mild steel and ebonite under longitudinal horizontal vibration are shown in Figs. 28-32. Results show that the friction coefficient increases almost linearly with the increase in amplitude of horizontal vibration for these materials. The increase of friction coefficient might be due to the increase of length of rubbing with the increase of amplitude of vibration. In addition to this the increase of friction coefficient $[39,43]$ is also associated with: (i) Fluctuation of inertia force along the direction of friction force (positive and negative). (ii) More sliding causes more abrasion resistance. Higher abrasion results more shearing due to penetration and ploughing of the asperities between contacting surfaces that might have some effect on the increment of friction force. (iii) Microwelding, reversal of friction vector, and mechanical interlocking. (iv) Formation and enhance an electrically charge layer at the interface. (v) Increase of solubility due to high temperature. 


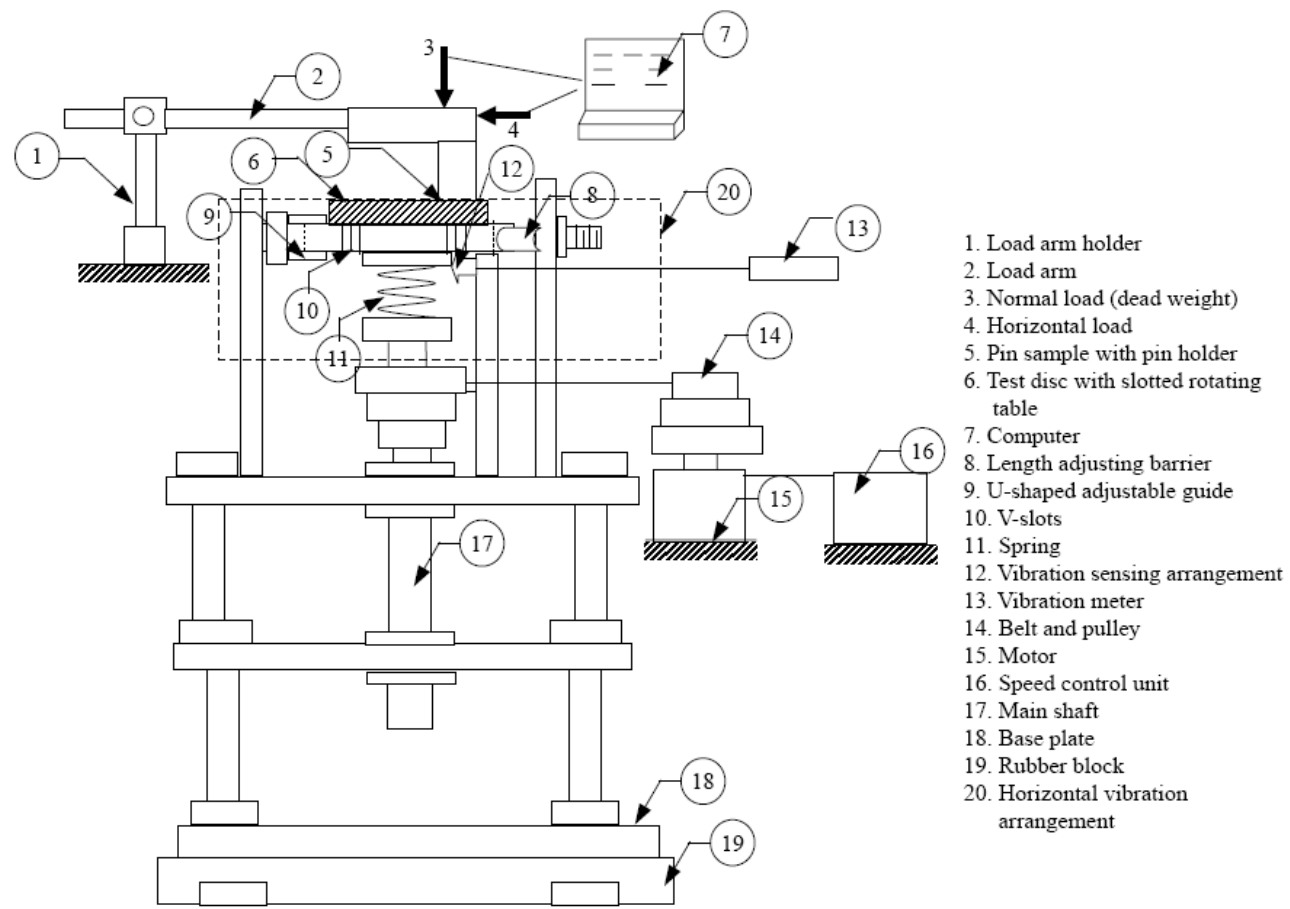

Figure 27. Block diagram of the experimental set-up for horizontal vibration

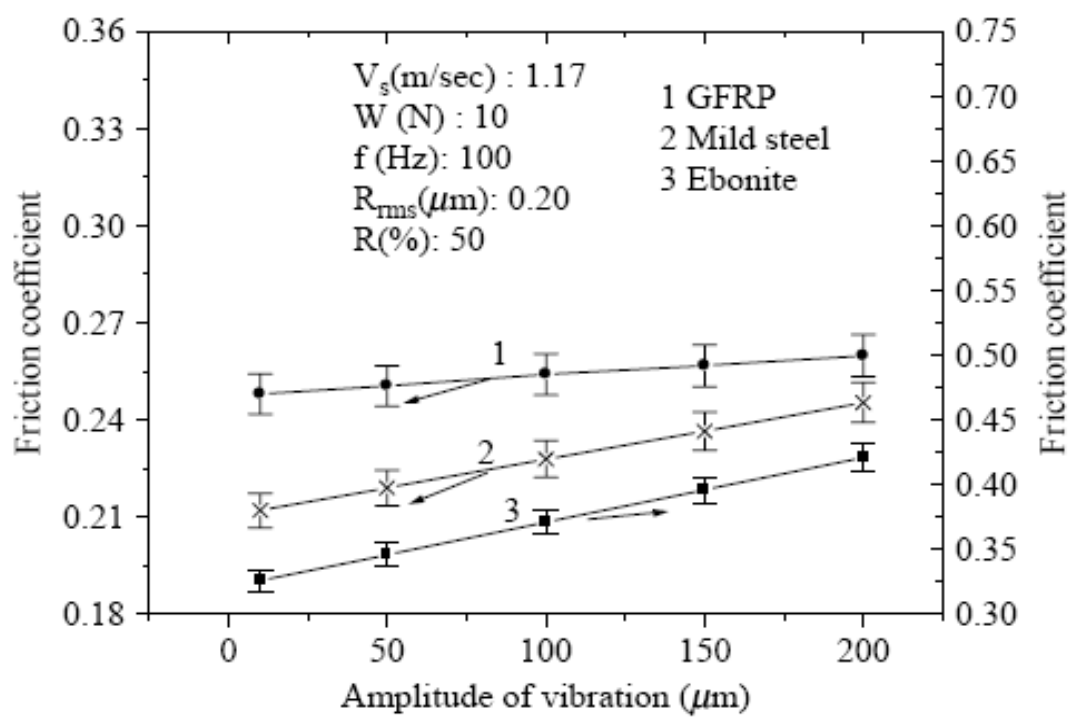

Figure 28. Variation of friction coefficient with the variation of amplitude of longitudinal vibration for frequency $100 \mathrm{~Hz}$ 


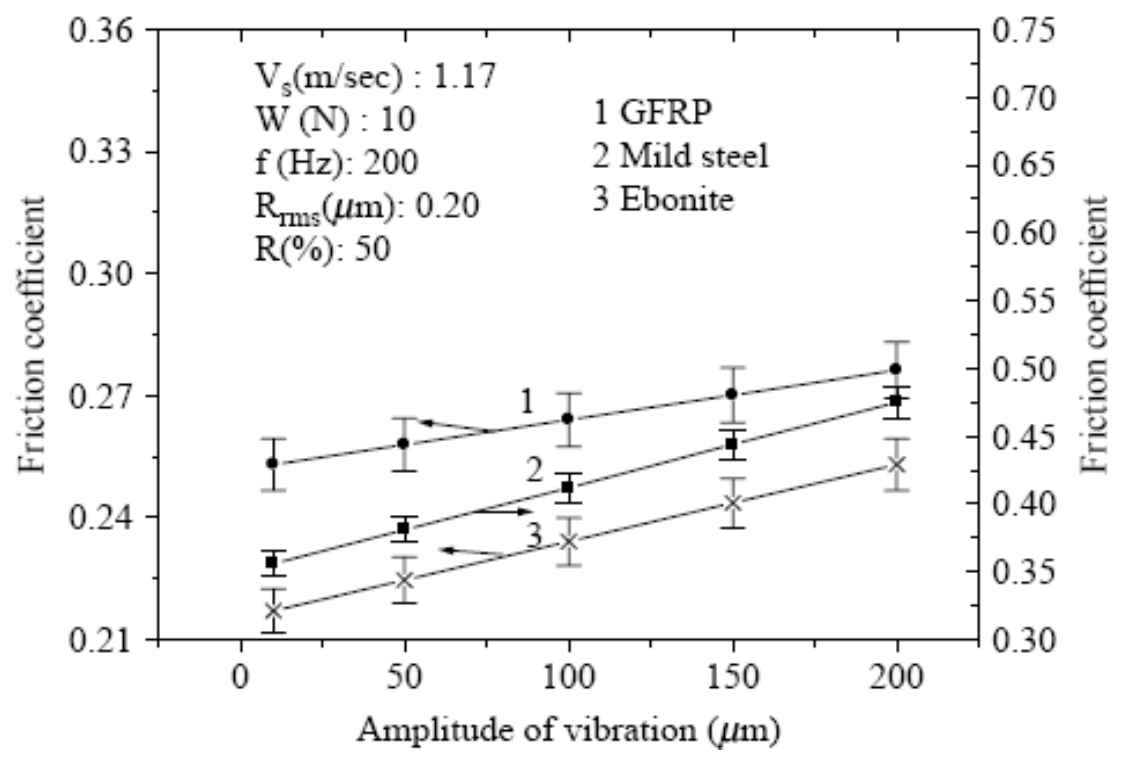

Figure 29. Variation of friction coefficient with the variation of amplitude of longitudinal vibration for frequency $200 \mathrm{~Hz}$

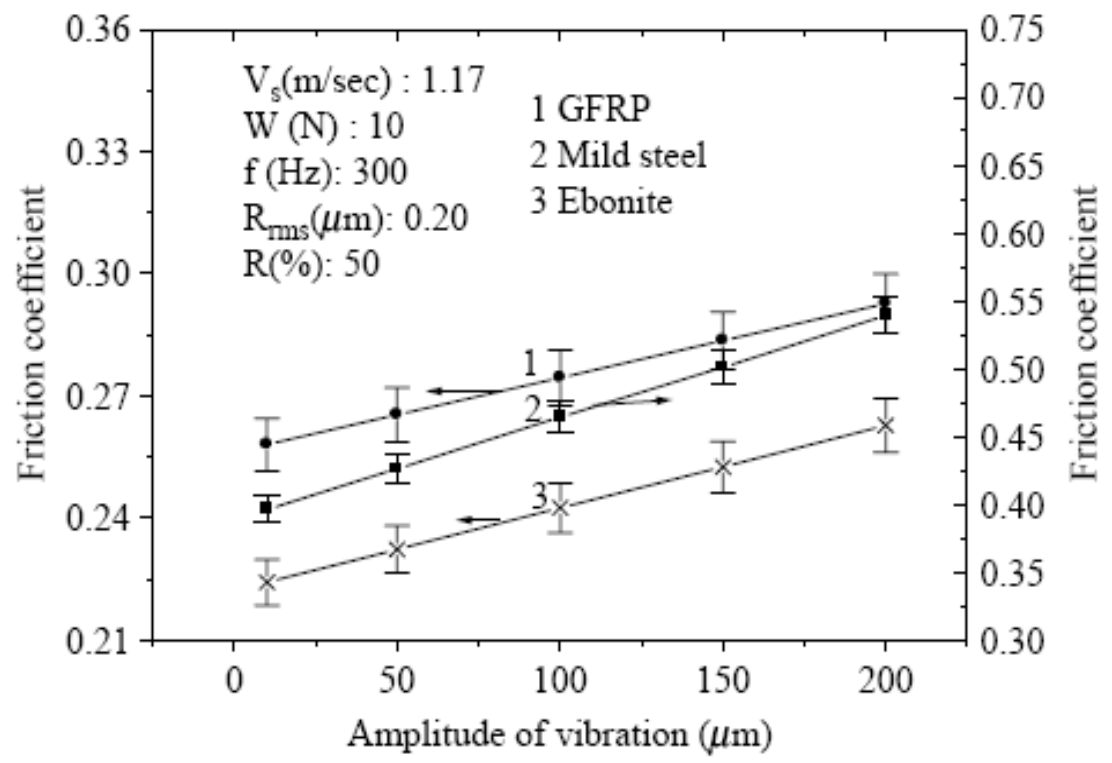

Figure 30. Variation of friction coefficient with the variation of amplitude of longitudinal vibration for frequency $300 \mathrm{~Hz}$ 


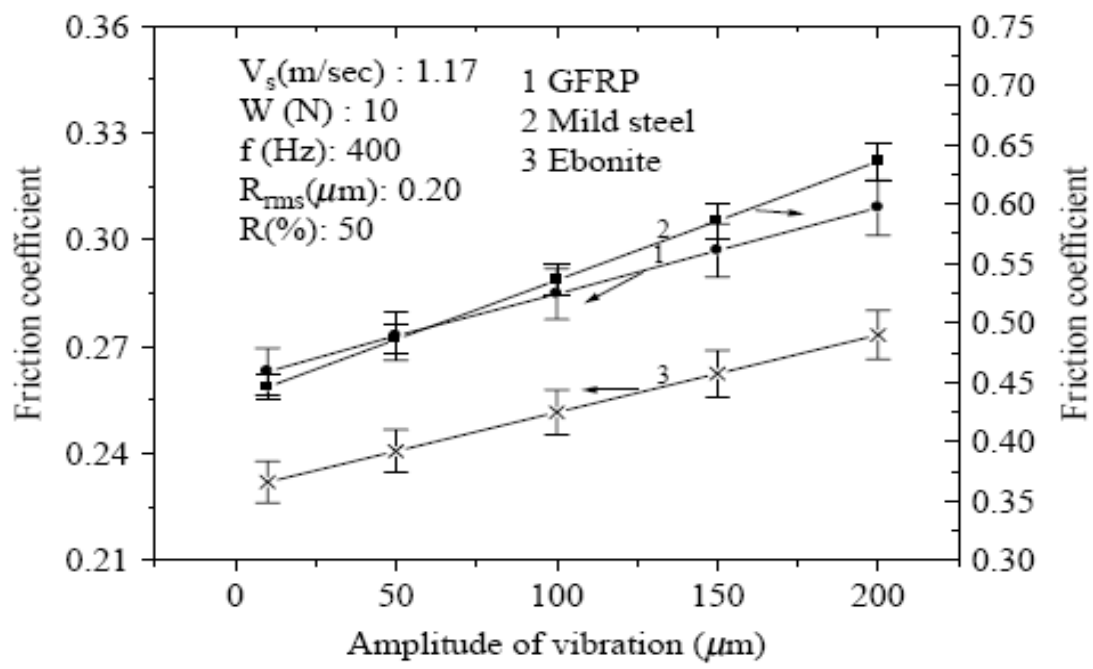

Figure 31. Variation of friction coefficient with the variation of amplitude of longitudinal vibration for frequency $400 \mathrm{~Hz}$

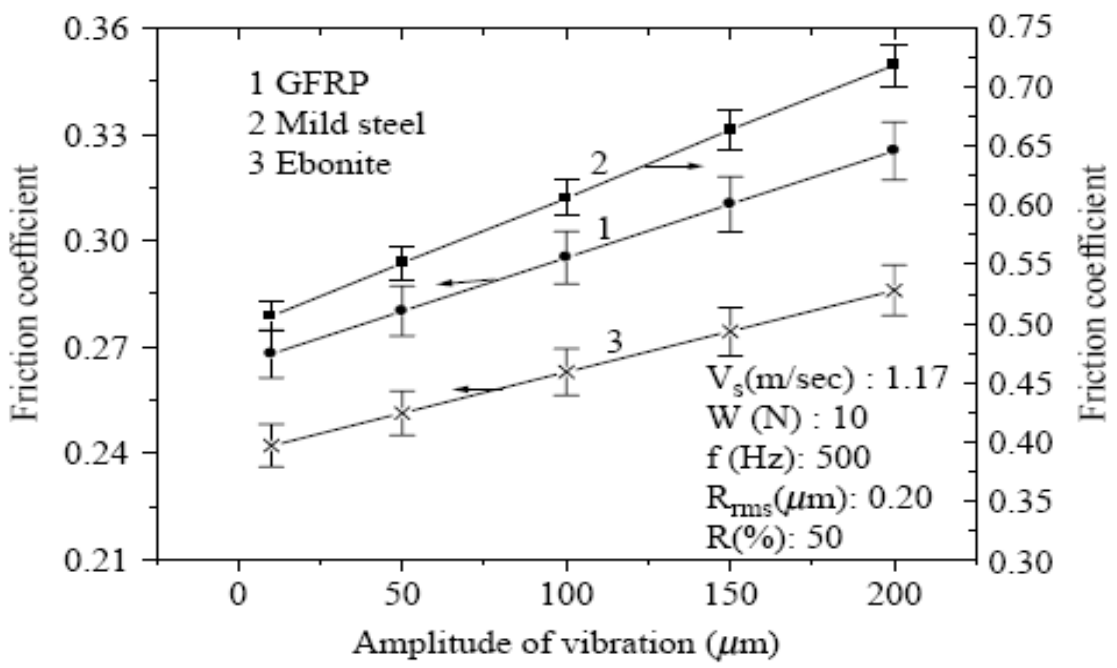

Figure 32. Variation of friction coefficient with the variation of amplitude of longitudinal vibration for frequency $500 \mathrm{~Hz}$

Results indicate that the magnitude and the slope of line of friction coefficient of mild steel under vibration condition are higher than that of GFRP and ebonite. It can be noted that the values of friction coefficient of mild steel are almost twice the values of ebonite and GFRP within the observed range of frequency of horizontal vibration. Under similar vibration conditions, the values of friction coefficient of GFRP are higher than that of ebonite [48]. Results also show that the friction coefficients obtained under transverse vibration are 
slightly higher than those of longitudinal vibrations. Changing of direction of inertia forces of the vibrating body and the effect of length of sliding path may be responsible for higher friction under transverse vibration [48].

\section{Effect of natural frequency on friction coefficient and wear rate}

The effects of natural frequency of the experimental set-up on the friction and wear of glass fiber are presented in this section. Figure 33 shows the variation of friction coefficient with the duration of rubbing at different natural frequencies of vibration for glass fiber. Results in Fig. 34 show that friction coefficient increases with the increase in natural frequency of vibration. If a body (either static or dynamic) is in contact with another moving (either rotation or translation) body, where the second body is vibrating, the contact of those two bodies takes place at some particular points of the second body instead of continuous contact. When the natural frequency of vibration of second body is more, for a constant length of contact, the contact points as well as the area of contact between two bodies will be more (Figure 35 (b)) compared to the situation when the natural frequency of second body is less (Figure 35 (a)). As the area of contact or the points of contact between two bodies are more, they experience more frictional resistance for a constant length of contact. Hence, the friction factor between the two bodies will increase with increased natural frequency [49].

The variation of wear and corresponding friction coefficient with the variation of natural frequency of the experimental set-up for glass fiber is presented in Fig. 36. Results show that wear rate as well as friction coefficient increases with the increase in natural frequency of vibration. The shear force and frictional thrust is increased with the increase in natural frequency of vibration and these increased values may accelerate the wear rate. The other possible causes are (i) high ploughing; and (ii) surface damage and breakage of reinforced fibers [50].

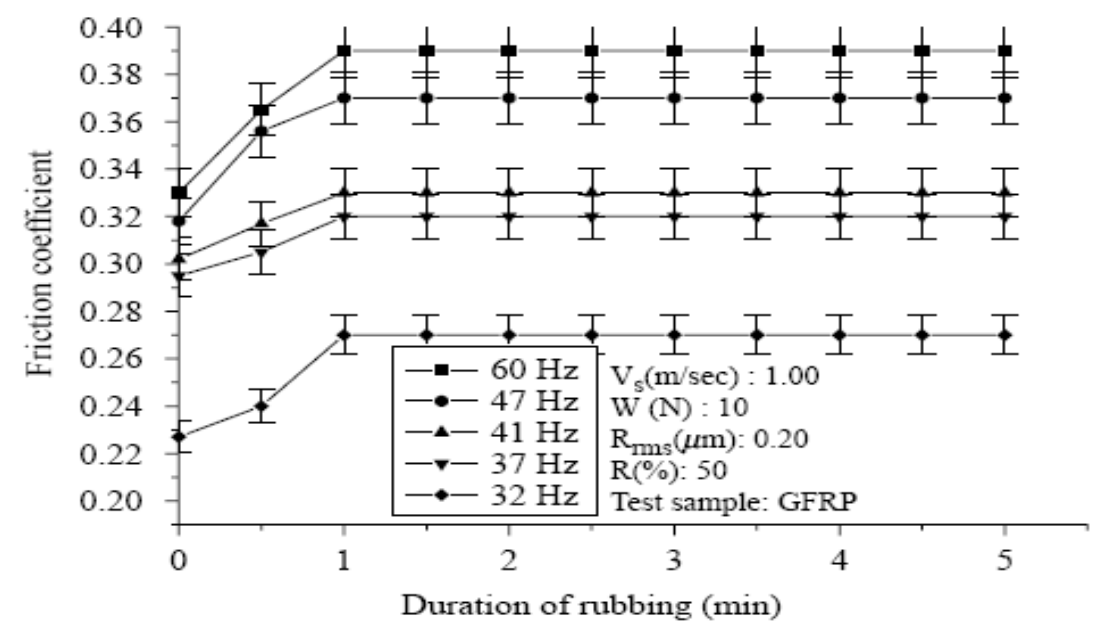

Figure 33. Variation of friction coefficient with the variation of natural frequency of the experimental set-up 


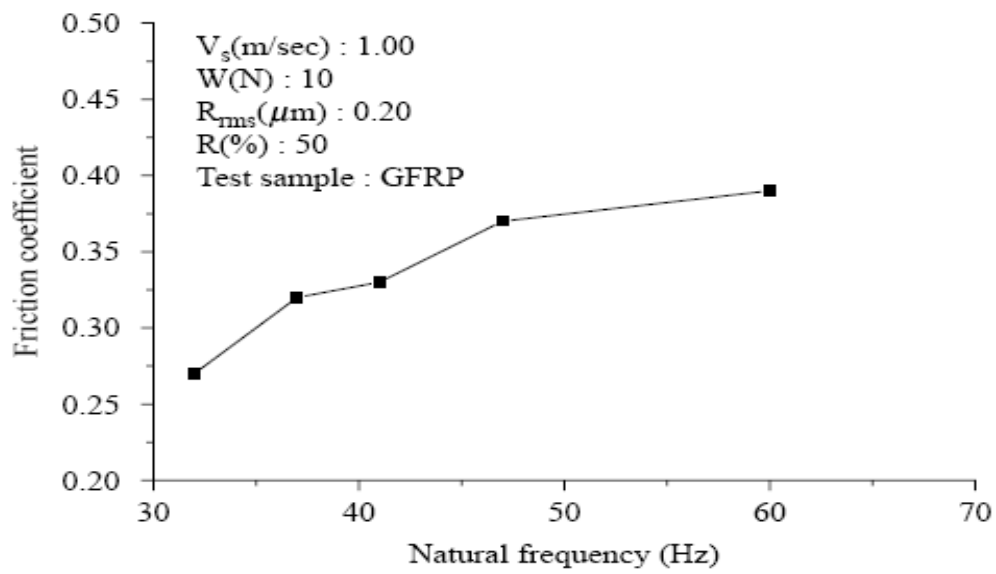

Figure 34. Variation of friction coefficient with the variation of natural frequency of the experimental set-up for GFRP

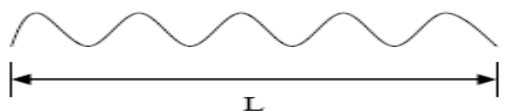

(a)

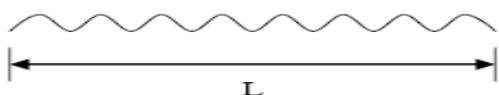

(b)

Figure 35. (a) The points of contact of a body with low natural frequency; (b) the points of contact of a body with high natural frequency for constant length of contact (L)

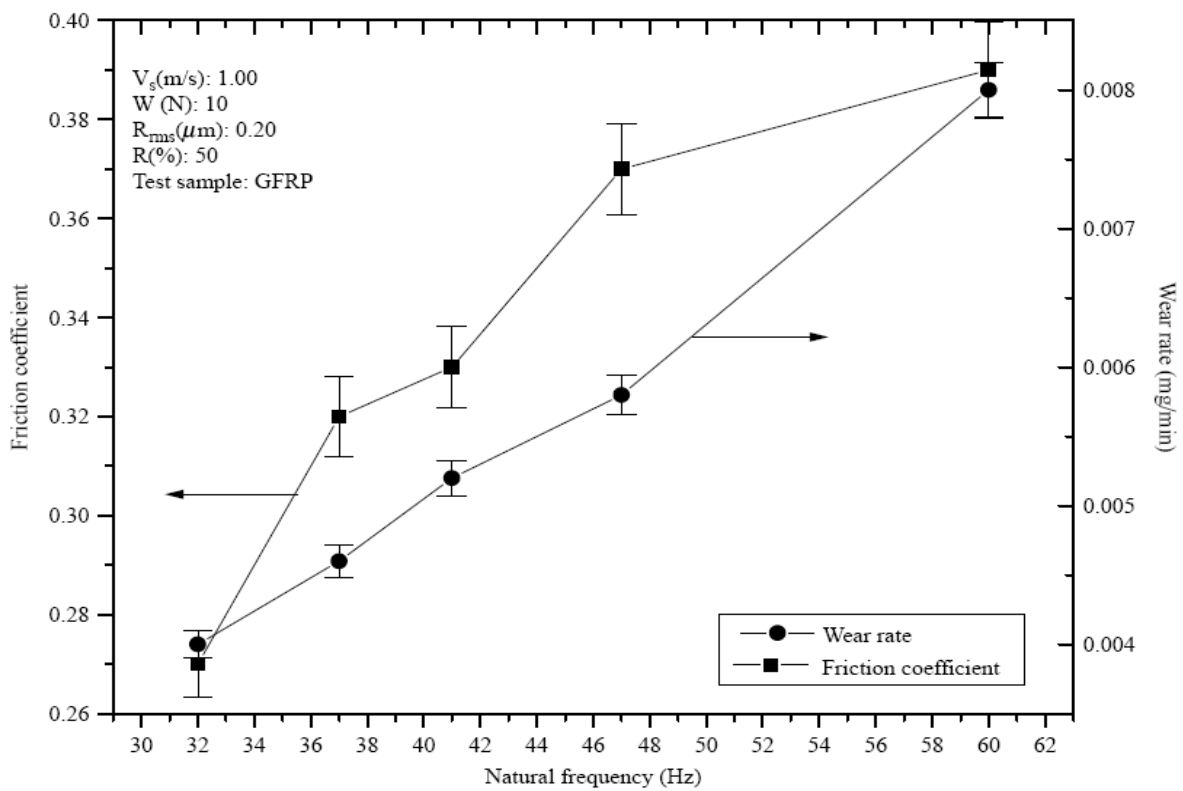

Figure 36. The variation of wear and corresponding friction coefficient with the variation of natural frequency of the experimental set-up for GFRP 


\section{Dimensionless relationship for friction and wear}

\subsection{Vertical vibration: Friction coefficient as a function of sliding velocity, amplitude and frequency of vibration}

The empirical formula of friction coefficient is derived from the dimensionless analysis to correlate the friction coefficient with sliding velocity, frequency and amplitude of vibration is expressed as [47]:

$$
\mu_{f}=k\left[\frac{A f}{V}\right]^{a}
$$

Where,

$\mu_{\mathrm{f}}=$ Friction coefficient

A = Amplitude

$\mathrm{V}=$ Sliding velocity

$\mathrm{f}=$ Frequency

' $a$ ' and ' $k$ ' are arbitrary constants

The dimensional friction parameter $\left[\frac{A f}{V}\right]$ is called 'Zaman Number' and abbreviated as Zn No.

Figures 37 and 38 show the plot of friction coefficient $\mu \mathrm{f}$ versus $\mathrm{Zn}$ no. for glass fiber and ebonite, respectively. Figures show that $\mu$ decreases linearly with the increase of $\mathrm{Zn}$ no. and are represented by the equations[47]:

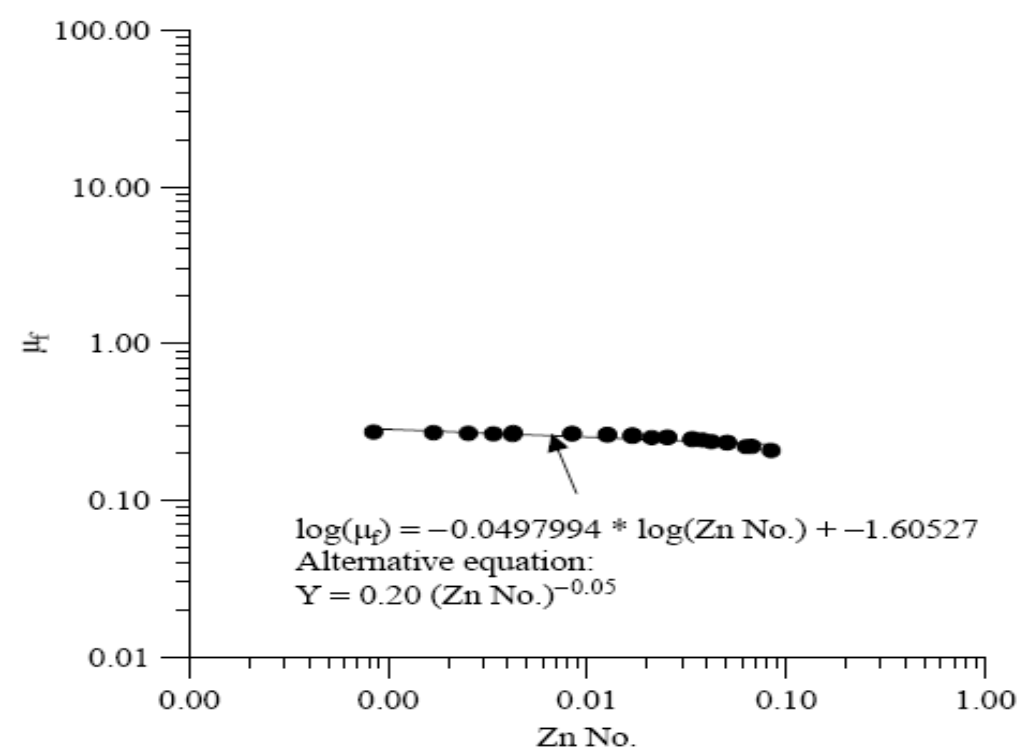

Figure 37. Friction coefficient as a function of $\mathrm{Zn}$ no. for GFRP 


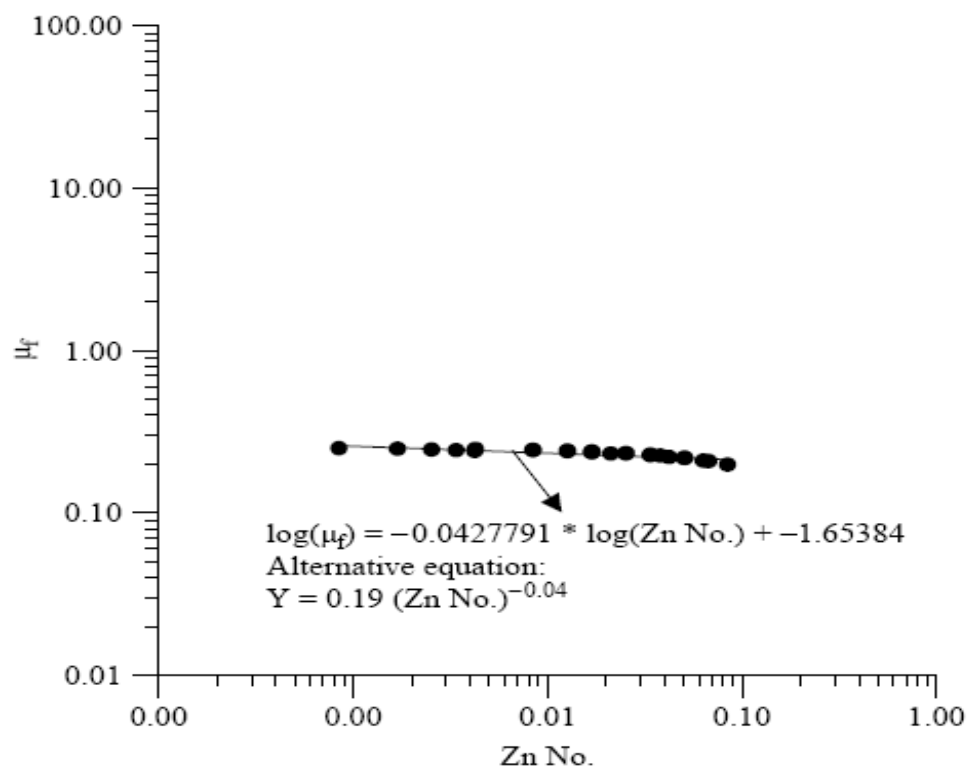

Figure 38. Friction coefficient as a function of $\mathrm{Zn}$ no. for ebonite

$\mu_{f}=0.20\left[\frac{A f}{V}\right]^{-0.05} \quad$ for glass fiber;

$\mu_{f}=0.19\left[\frac{A f}{V}\right]^{-0.04} \quad$ for ebonite

The maximum percentage variation between experimental and theoretical results for GFRP and ebonite are almost $\pm 5 \%$ within the observed range of $\mathrm{Zn}$ no. The coefficient of determination of GFRP and ebonite are $72 \%$ and $75 \%$ respectively. This indicates that experimental results are in good agreement with the theoretical calculations.

\subsection{Horizontal vibration: Friction coefficient as a function of sliding velocity, amplitude and frequency of vibration}

Figures 39 and 40 show the plot of friction coefficient $\mu \mathrm{f}$ versus $\mathrm{Zn}$ no. for GFRP and ebonite, respectively. Results show that $\mu$ increases linearly with the increase of $\mathrm{Zn}$ no. and are expressed by the equations for external horizontal vibration [48]:

$\mu_{f}=0.34\left[\frac{A f}{V}\right]^{0.05} \quad$ for glass fiber;

$\mu_{f}=0.31\left[\frac{A f}{V}\right]^{0.06} \quad$ for ebonite 


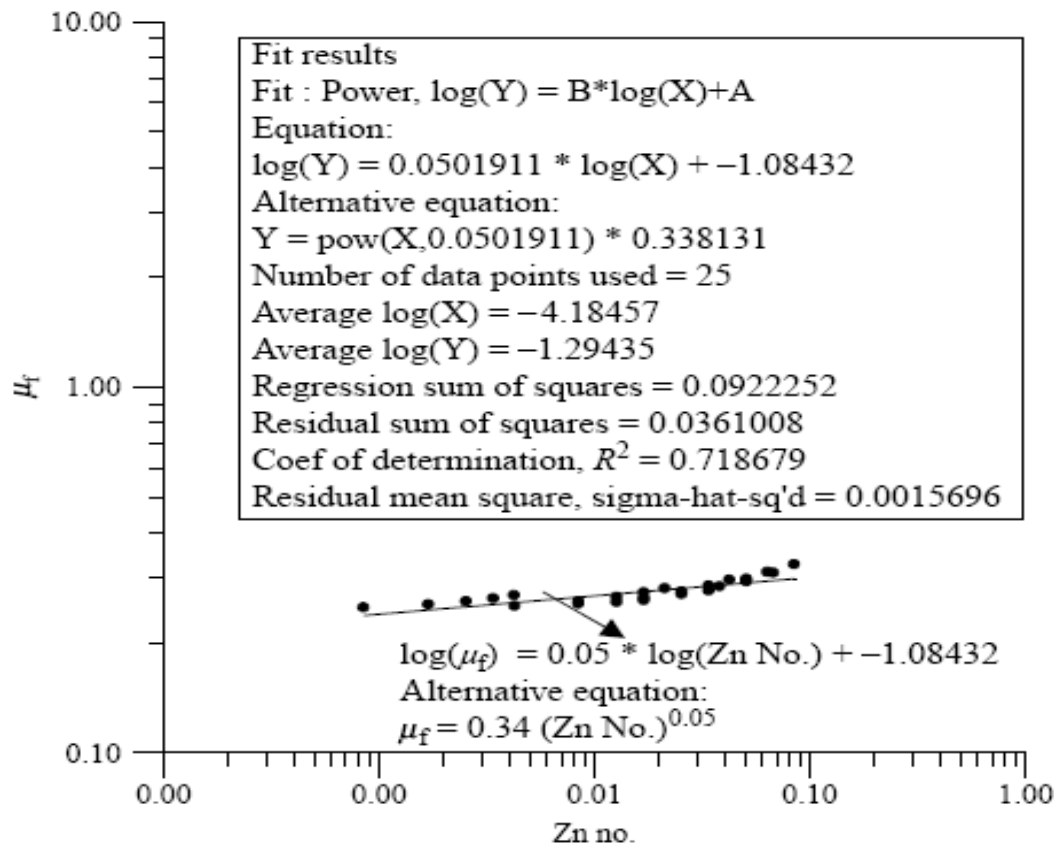

Figure 39. Friction coefficient as a function of $\mathrm{Zn}$ no. for GFRP

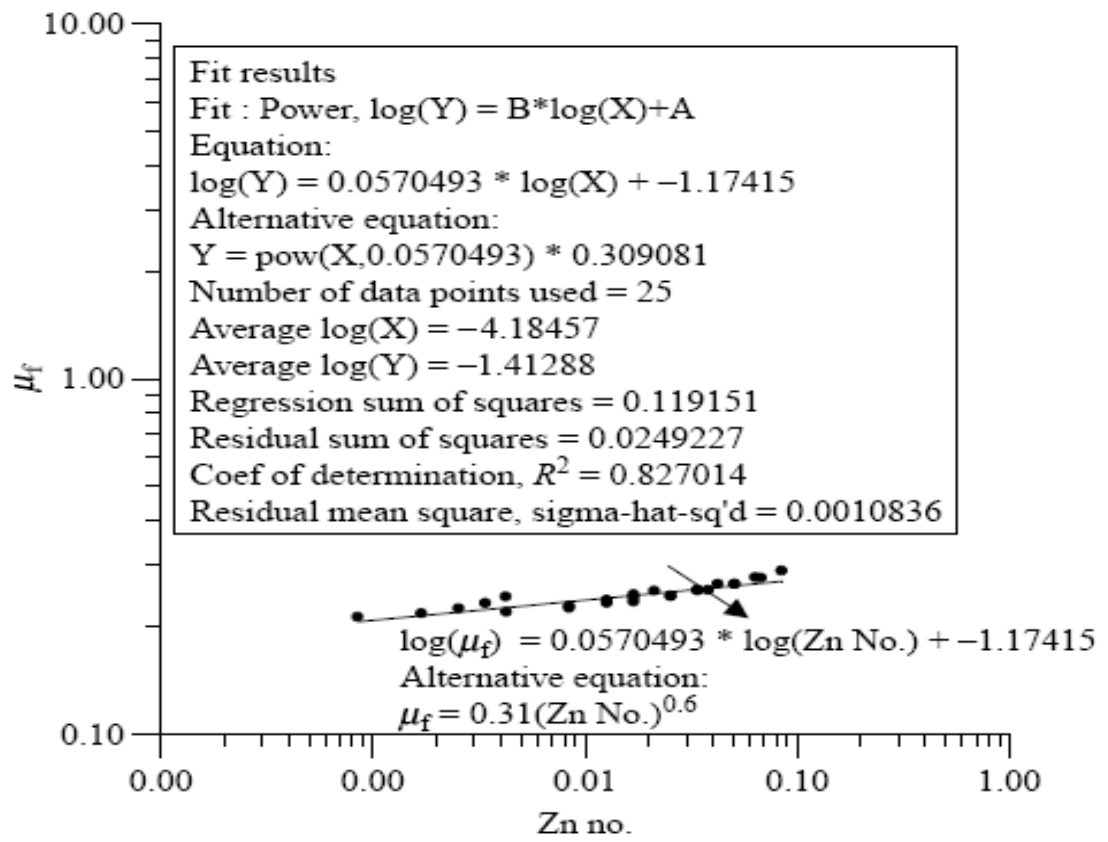

Figure 40. Friction coefficient as a function of $\mathrm{Zn}$ no. for ebonite 


\subsection{Wear rate as a function of natural frequency, sliding velocity, normal load and surface roughness}

The empirical formula of wear rate is derived from the dimensional analysis to correlate wear rate with natural frequency, roughness and sliding velocity is expressed as [50]:

$$
W_{r}=\frac{k N}{f_{n} R}\left[\frac{f_{n} R}{V}\right]^{-b}
$$

Where,

$\mathrm{W}_{\mathrm{r}}=$ Wear rate $=\mathrm{Mt}^{-1}$

$\mathrm{f}_{\mathrm{n}}=$ Natural frequency $=\mathrm{t}^{-1}$

$\mathrm{V}=$ Sliding velocity $=\mathrm{Lt}^{-1}$

$\mathrm{N}=$ Normal load $=\mathrm{MLt}^{-2}$

$\mathrm{R}=$ Root mean square roughness of the tested surface $=\mathrm{L}$

' $\mathrm{b}$ ' and ' $\mathrm{k}$ ' are arbitrary constants

The dimensional wear parameter $\frac{f_{n} R}{V}$ is called 'Asad Number' and abbreviated as Ad No.

Figure 41 shows the plot of wear rate $W_{\mathrm{r}}$ versus Ad No. Results indicate that $\mathrm{W}_{\mathrm{r}}$ increases linearly with the increase of Ad. No. and is represented by the equation:

$$
\mathrm{Wr}=-6.52579 \mathrm{E}-4+711.092\left[\frac{f_{n} R}{V}\right]
$$

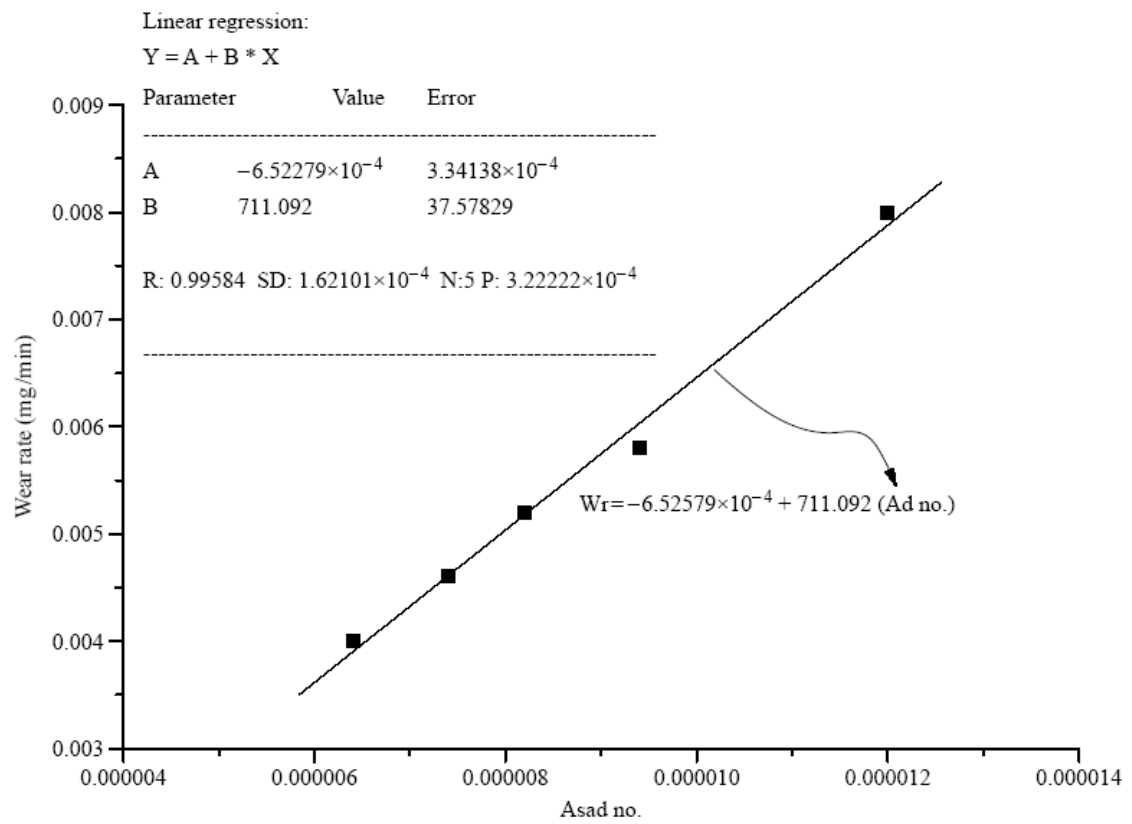

Figure 41. Wear rate as a function of Asad number 
The coefficient of determination for the relationship between wear rate and Ad No. is almost $99 \%$. That is, trend line or Ad. No. can explain $99 \%$ of the variation in wear rate. This means that experimental results are in good agreement with the theoretical calculations [50].

\section{Summary}

Friction and wear of polymer and composites are significantly influenced by normal load, sliding velocity, amplitude of vibration, frequency of vibration, direction of vibration and natural frequency. Friction coefficient also depends on duration of rubbing and it is different for different materials. Friction coefficient can be increased or decreased depending on sliding pairs and operating parameters. There are also some correlations between friction/wear and other influencing parameters. The current trends of these experimental and analytical results can be used in future to design different tribological and mechanical components. The researchers can use these results to innovate some design strategies for improving different concerned mechanical processes. It is expected that the research findings of tribological behavior of polymer and composites discussed in this chapter will also be used for future research and development.

\section{Author details}

Dewan Muhammad Nuruzzaman* and Mohammad Asaduzzaman Chowdhury Department of Mechanical Engineering, Dhaka University of Engineering and Technology (DUET), Gazipur, Gazipur, Bangladesh

\section{References}

[1] Zhang, S. W. State-of-the-art of polymer tribology. Tribology International, 1998; 31 (13): 49-60.

[2] Yamaguchi Y., Tribology of plastic materials: their characteristics and applications to sliding components. Amsterdam: Elsevier 1990.

[3] Hooke, C. J., Kukureka, S. N., Liao, P., Rao, M., and Chen, Y. K. The friction and wear of polymers in non-conformal contacts. Wear 1996; 200: 83-94.

[4] Lawrence, C. C., and Stolarski, T. A. Rolling contact wear of polymers: a preliminary study. Wear 1989; 132: 83-91.

[5] J.F. Archard, Wear theory and mechanisms. Wear Control Handbook, ASME, New York, 1980.

[6] D. Tabor, Friction and wear - developments over the last 50 years, keynote address, Proceedings, International Conference of Tribology - Friction, Lubrication and Wear, 50 years on, London, Institute of Mechanical Engineering (1987) 157-172.

[7] Chowdhury MA, Helali MM. The effect of frequency of vibration and humidity on the coefficient of friction. Tribol Int 2006;39:958-62.

\footnotetext{
${ }^{*}$ Corresponding Author
} 
[8] N.S.M. El-Tayeb, I.M. Mostafa, The effect of laminate orientations on friction and wear mechanisms of glass reinforced polyester composite. Wear 195 (1996) 186-191.

[9] N.S.M. El-Tayeb, R.M. Gadelrab, Friction and wear properties of E-glass fiber reinforced epoxy composites under different sliding contact conditions. Wear 192 (1996) 112-117.

[10] S. Bahadur, Y. Zheng, Mechanical and tribological behavior of polyester reinforced with short glass fibers. Wear 137 (1990) 251-266.

[11] S. Bahadur, V.K. Polineni, Tribological studies of glass fabric-reinforced polyamide composites filled with CuO and PTFE. Wear 200 (1996) 95-104.

[12] Watanabe, M. The friction and wear Properties of nylon. Wear 1968; 110: 379-388.

[13] Tanaka, K. Transfer of semicrystalline polymers sliding against smooth steel surface. Wear 1982; 75: 183 - 199.

[14] Bahadur, S., and Tabor, D. Role of fillers in the friction and wear behavior of highdensity polyethylene. In: Lee LH, editor. Polymer wear and its control. ACS Symposium Series, Washington DC 1985; 287: 253-268.

[15] Pihtili, H., and Tosun, N. Investigation of the wear behavior of a glass fiber-reinforced composite and plain polyester resin. Composites Science and Technology, 2002; 62:367370.

[16] Pihtili, H., and Tosun, N. Effect of load and speed on the wear behavior of woven glass fabrics and aramid fiber-reinforced composites. Wear, 2002; 252:979-984.

[17] Santner, E., and Czichos, H. Tribology of polymers. Tribology International 1989; 22(2): 103-109.

[18] Tevruz, T. Tribological behaviours of bronze-filled polytetrafluoroethylene dry journal bearings. Wear 1999; 230: 61-69.

[19] Tevruz, T. Tribological behaviours of carbon-filled polytetrafluoroethylene dry journal bearings. Wear 1998; 221: 61-68.

[20] Anderson, J. C. The wear and friction of commercial polymers and composites. In: Friction and wear and polymer composites. Friedrich K, editor. Composite materials series, vol. 1. Amsterdam: Elsevier 1986; 329-362.

[21] Unal, H., Mimaroglu, A., Kadioglu, U., and Ekiz, H. Sliding friction and wear behaviour of polytetrafluoroethylene and its composites under dry conditions. Materials and Design 2004; 25: 239 - 245.

[22] Sirong, Yu, Zhongzhen, Yu, and Yiu-Wing, Mai. Effects of SEBS-g-MA on tribological behavior of nylon 66/organoclay nanocomposites. Tribology International 2007; 40: 855 -862 .

[23] Stuart, B. H. Tribological studies of poly(ether ether ketone) blends. Tribology International 1998; 31(11): 647-651.

[24] Unal, H., and Mimaroglu, A. Influence of test conditions on the tribological properties of polymers. Industrial Lubrication and Tribology 2003; 55(4): 178-183.

[25] Unal, H., and Mimaroglu, A. Friction and wear behavior of unfilled engineering thermoplastics. Material Design 2003; 24: 183-187.

[26] Suresha, B., Chandramohan, G., Prakash, J.N., Balusamy, V., and Sankaranarayanasamy, K. The role of fillers on friction and slide wear characteristics in 
glass-epoxy composite systems. Journal of Minerals \& Materials Characterization \& Engineering 2006; 5 (1): 87 - 101.

[27] Mimaroglu, A., Unal, H., and Arda, T. Friction and wear performance of pure and glass fiber reinforced Poly-Ether-Imide on polymer and steel counterface materials. Wear 2007; 262: 1407 - 1413.

[28] Unal, H., Mimaroglu, A., Kadioglu, U., and Ekiz, H. Sliding friction and wear behaviour of polytetrafluoroethylene and its composites under dry conditions. Materials and Design 2004; 25: 239 - 245.

[29] Unal, H., Sen, U., and Mimaroglu A. An approach to friction and wear properties of polytetrafluoroethylene composite. Materials and Design, 2006; 27: 694-699.

[30] El-Tayeb, N. S. M., Yousif, B. F., and Yap, T. C. Tribological studies of polyester reinforced with CSM 450-R-glass fiber sliding against smooth stainless steel counterface. Wear, 2006; 261:443-452.

[31] Wang, Y.Q., and Li, J. Sliding wear behavior and mechanism of ultra-high molecular weight polyethylene. Materials Science and Engineering, 1999; 266:155-160.

[32] Tsukizoe, T., and Ohmae, N. Friction and wear of advanced composite materials. Fiber Science and Technology, 1983; 18 (4): 265-286.

[33] Suresha, B., Chandramohan, G., Samapthkumaran, P., Seetharamu, S., and Vynatheya, $\mathrm{S}$. Friction and wear characteristics of carbon-epoxy and glass-epoxy woven roving fiber composites. Journal of Reinforced Plastics and Composites 2006; 25: 771-782.

[34] Godfrey, D. (1967), "Vibration reduces metal to metal contact and causes an apparent reduction in friction", ASME Transactions, Vol. 10, pp. 183-92.

[35] Tolstoi, D.M., Borisova, G.A. and Grigorova, S.R. (1973), "Friction reduction by perpendicular oscillations", Soviet Physics-Doklady, Vol. 17, pp. 907-9.

[36] Lenkiewicz, W. (1969), "The sliding process - effect of external vibrations", Wear, Vol. 13, pp. 99-108.

[37] Hess, D.H. and Soom, A. (1991), "Normal vibrations and friction under harmonic loads: Part I - Hertzian contacts", Journal of Tribology, Vol. 113, pp. 80-6.

[38] Budanov, B.V., Kudinov, V.A. and Tolstoi, D.M. (1980), "Interaction of friction and vibration", Soviet Journal of Friction and Wear, Vol. 1, pp. 79-89.

[39] Skare, T. and Stahl, J. (1992), "Static and dynamic friction processes under the influence of external vibrations", Wear, Vol. 154, pp. 177-92.

[40] Nuruzzaman, D.M., Chowdhury, M.A., and Rahaman, M.L. Effect of Duration of Rubbing and Normal Load on Friction Coefficient for Polymer and Composite Materials. Industrial Lubrication. and Tribology 2011; 63: 320 - 326.

[41] Cho M.H., Bahadur, S. and Pogosian A.K. Friction and wear studies using Taguchi method on polyphenylene sulfide filled with a complex mixture of MoS2, Al2O3, and other compounds. Wear 2005; 258: 1825-1835.

[42] Bahadur, S. The development of transfer layers and their role in polymer tribology Wear 2000; 245: 92-99.

[43] Bhushan, B. Principle and Applications of Tribology. John Wiley \& Sons, Inc., New York, 1999. 
[44] Nuruzzaman, D.M., Rahaman, M.L. and Chowdhury, M.A. Friction coefficient and wear rate of polymer and composite materials at different sliding speeds. International Journal of Surface Science and Engineering 2012 (in press).

[45] Unal, H, Sen U and. Mimaroglu A. Dry sliding wear characteristics of some industrial polymers against steel counterface Tribology International 2004; 37: 727-732.

[46] Chowdhury M.A.and Helali M.M. The Effect of Amplitude of Vibration on the Coefficient of Friction for Different Materials Tribology International 2008;41: 307- 314.

[47] Chowdhury MA and Helali MM. The frictional behavior of materials under vertical vibration. Industrial Lubrication. and Tribology 2009;61:154-160.

[48] Chowdhury MA and Helali MM. The frictional behavior of composite materials under horizontal vibration. Industrial Lubrication. and Tribology 2009;61:246-253.

[49] Chowdhury MA, Ali M and Helali MM. The effect of natural frequency of the experimental set-up on the friction coefficient Industrial Lubrication. and Tribology 2010;62:78-82.

[50] Chowdhury MA. The effect of natural frequency of the experimental set-up on the wear rate Industrial Lubrication. and Tribology 2010;62:356-360. 